This item was submitted to Loughborough's Research Repository by the author.

Items in Figshare are protected by copyright, with all rights reserved, unless otherwise indicated.

\title{
Changes in the relationship between short-term interest rate, inflation and growth: evidence from the UK, 1820-2014
}

\section{PLEASE CITE THE PUBLISHED VERSION}

https://doi.org/10.1111/boer.12199

\section{PUBLISHER}

(c) Board of Trustees of the Bulletin of Economic Research and John Wiley \& Son

\section{VERSION}

AM (Accepted Manuscript)

\section{PUBLISHER STATEMENT}

This is the peer reviewed version of the following article: BATAA, E., VIVIAN, A.J. and WOHAR, M.E., 2019. Changes in the relationship between short-term interest rate, inflation and growth: evidence from the UK, 1820-2014. Bulletin of Economic Research, 71(4), pp. Pages 616-640, which has been published in final form at https://doi.org/10.1111/boer.12199. This article may be used for non-commercial purposes in accordance with Wiley Terms and Conditions for Use of Self-Archived Versions

\section{LICENCE}

CC BY-NC-ND 4.0

\section{REPOSITORY RECORD}

Bataa, Erdenebat, Andrew Vivian, and Mark Wohar. 2019. "Changes in the Relationship Between Short-term Interest Rate, Inflation and Growth: Evidence from the UK, 1820-2014”. Loughborough University. https://hdl.handle.net/2134/38157. 
Changes in the relationship between short-term interest rate, inflation and growth: Evidence from the UK, 1820-2014

October 2018 


\section{Introduction}

Economic growth, inflation and the short-term interest rate are key macroeconomic variables. They feature in numerous economic models and are clearly linked via the Taylor rule. The short-term interest rate is closely related to the economic policy rate set by central banks (or governments). Arguably, the primary tool used by policymakers to manage the macroeconomy is the interest rate. There is widespread support that interest rates respond to both inflation and economic activity (interest rates lag these variables) but also that interest rates themselves impact inflation and economic activity (interest rates lead these variables). However, until recently there has been little work that has examined the time-variation in the relationships between these variables. This is surprising given there have been dramatic changes in the macroeconomy during recent decades. This paper implements the methods of Bataa, Osborn, Sensier and Dijk (2013) and Bataa, Osborn and Sensier (2018) which test for structural breaks in the autoregressive coefficients and the variance-covariance matrix of the VAR; this enables us to uncover substantial time-variation in the interrelationships of these key economic variables using impulse response functions and forecast error variance decompositions.

It is well established that growth, inflation and interest rates should be related. For example, growth can stimulate inflation via the well-known demand-pull inflation channel. The Fisher effect indicates a positive relationship between inflation and nominal interest rates, although most literature reports a response of interest rates to inflation which is much less than unity implying a slow adjustment (see e.g. Mishkin, 1992; Evans and Lewis, 1995). There is also a strong link between short-term nominal interest rates and real output (e.g. Bernanke and Blinder, 1992); Fuhrer and Moore (1995) provide a model which suggests this could be theoretically justified when short-term nominal interest rates behave like long-term real interest rates. There is also evidence that inflation has a negative effect on growth across countries (Gylfason and Herbertsson, 2001; Barro, 2013; amongst others). However, other literature suggests this negative effect on growth is primarily apparent at high inflation rates (Sarel, 1996; Ghosh and Phillips, 1998; Khan and Senhadji, 2001; amongst others). Consequently, there can be structural breaks in the relationships of these key economics variables.

Prior empirical work has attempted to help us better understand the dynamic linkages of inflation, interest rates, and economic growth, by employing methodologies that allow for the possibility of structural shifts in the parameters of the model. In their investigation of inflation 
dynamics Cogley, Primiceri, and Sargent (2008) and Cogley and Sargent (2002, 2005) employ a time-varying parameter Vector Autoregression (TVP-VAR) to investigate the possibility of shifts in the dynamics of inflation. Benati (2008a) applies the same methodology to the modelling of the temporal shifts in UK macroeconomic dynamics. Sims and Zha (2006) model changes in US macroeconomic dynamics using a regime-switching VAR (see Groen and Mumtaz, 2008, for an investigation of the UK). Balke (2000) provides evidence of non-linearities that exist in the dynamics of output and inflation by implementing a threshold VAR (TVAR) model. More recent research have estimated time-varying factor augmented VAR (TVPFAVAR) models in an effort to incorporate more information into the empirical model. For example, Baumeister, Liu, and Mumtaz (2013) argue that incorporating a large information set can be important when modelling changes in the monetary transmission mechanism and use a TVPFAVAR to estimate the evolving response to US monetary policy shocks.

This paper implements the methods of Bataa et al. $(2013,2018)$ which extends the above literature in a number of important ways. As emphasized in Bataa, Izzeldin and Osborn (2016), our formal structural break analysis provides complementary information to TVP-VAR studies, allowing for discrete breaks of unknown number and, in particular, permitting the null hypothesis of no change to be explicitly considered. A discrete break test of the type that we use is known to have power against other alternatives, such as one in which the coefficients follow a random walk (see Stock and Watson, 1998 and Boivin and Giannoni, 2006). While the continuous change implied by the random walk assumption is flexible in modeling terms, it results in a loss of estimation accuracy if employed in a period of constant coefficients.

To the best of our knowledge, the present paper is the first to apply formal statistical tests to examine the existence and nature of change in both the autoregressive coefficients and the variance-covariance matrix of a reduced form monetary policy VAR model. In other words, rather than assuming either constant parameters or change at specific dates, we let the data speak and provide the number of discrete structural breaks and their timing. Further, since parameters are constant in our model within regimes, we are able to construct conventional confidence intervals for impulse response functions and forecast error variance decompositions, whereas these tools have limited applicability in a model with continuous change. For these reasons, we prefer to test for parameter change (or structural breaks), rather than impose either continuous change or to (perhaps arbitrarily and potentially incorrectly) pre-specify the date or dates at which change may occur. 
The approach in this paper also allows for outliers and structural breaks in the levels of the series to be neutralised before conducting empirical analysis. This enables relationships between our key variables of interest and their time-variation to be more reliably examined since series with outliers or structural breaks in them can substantially distort empirical results (e.g. Lettau and van Nieuwerburgh, 2008).

We model the dynamic behavior of the short-term interest rate, inflation and economic growth over the period 1820-2014 for the United Kingdom. Our empirical findings indicate several structural breaks in the relationship, which lead to very different inference compared to a constant parameter model. We find that interest rates respond much more strongly to growth and inflation over the recent decades, which is also indicated by Forecast error variance decomposition analysis that finds the variables have become increasingly interconnected in recent years. To be more specific we find that most covariance matrix breaks can be primarily attributed to changes in volatility, although these mainly occur prior to the end of WWI. We also find that prior to WWI that the interrelationships between the three variables studied were weak compared to recent decades as highlighted by the IRFs. This appears to be due to a structural break in the persistence of all three variables in 1917 (when persistence increased) and also from a volatility break in the covariance matrix (volatility increased). There is also very strong evidence that the dynamic relationship between inflation and the short rate breaks down during the WW II; there is some evidence of Granger causality from the growth rate to the short rate which also changed during this period. Our results confirm earlier research that a great moderation occurred but suggests that the structural change is apparent in 1952 in the UK annual data. We do find a covariance matrix break in 1989 but this can be attributed to a break in correlation rather than a break in volatility. The finding that there has been no significant structural break in the correlation between the short term interest rate, inflation and growth until 1989 is indeed one of the most interesting.

An important finding from our analysis, that earlier studies were not able to examine, is that the dynamic behaviour of our variables of interest have been distinctly different in recent decades compared to earlier sub-samples. We find that the short rate responds strongly to both growth post-1975 and to inflation since at least 1990. However, short rate shocks do not have substantial negative impacts either upon the growth rate or inflation over recent years. The implication is that the effectiveness and role of the short term interest as a tool for policymakers may need to be reconsidered. This is because empirical results for the UK indicate that a very 
large change in the interest rate would be necessary for there to be a substantial impact on growth or on inflation. Anecdotally we have seen the unprecedented declines in interest rates during 2008-2009 did not have the strong impact on output that was hoped for. This may be a consequence of the monetary policy regime (inflation / money supply targeting) adopted where interest rates are adjusted in response to shocks to growth and inflation; therefore these variables are now highly interconnected.

Overall, we find that there is evidence of substantial structural change over time in the relationship between growth, inflation and the short rate. The primary findings are i) most covariance matrix breaks are attributable to variance shifts and ii) when a correlation break did occur this lead to a substantial intensification of the responsiveness of the short rate to growth and inflation, which is observed for recent decades and FEVDs indicate an increased connectedness of the variables at one-year horizon. Consequently, economic policymakers need to carefully monitor the linkages between these variables and be prepared to adjust the way monetary tools are used when faced with structural change.

The outline of the paper is as follows. Section 2 provides a description and overview of the data used in the main analysis. Then in section 3 we discuss our multivariate econometric technique that deals with structural breaks in the relationship between these variables. The structural break test results are in section 4 while our main empirical results are presented in section 5 and we conclude in section 6 .

\section{Data and Preliminary Analysis}

Our empirical analysis is based upon an extremely long time-series of annual UK data covering the period 1820-2014 from Officer (2015) as plotted in Figure 1. The main variables of interest are the nominal short-term interest rate, retail price index inflation and real economic growth. ${ }^{1}$ There are two main reasons for selecting this data. First, an important consideration for low frequency analysis of financial data is the length of the series. That is, the number of years covered in the sample is of much greater consequence than the number of observations per se. (Shiller and Perron, 1985, Davidson and MacKinnon, 1993). Second, given our focus on inflation in this study and the tendency for this to be generally calculated as a year-on-year change due

\footnotetext{
${ }^{1}$ Officer (2015) provides two types of short term interest rates since 1790: one is contemporary and the other is consistent; they are exactly the same after 1919. We choose the contemporary series but their correlation from 1820 to 1918 is quite high, $99.6 \%$.
} 
to seasonality issues makes an annual sampling of data preferable. Due to differencing of the log real GDP and log RPI the starting date of our main analysis coincides with the establishment of the formal Gold Standard in 1821, when Britain adopted it following the introduction of the gold sovereign by the new Royal Mint at Tower Hill in 1816 .

Lutkepohl (1989) show that Granger causality (GC) tests over-reject in finite samples when mean breaks are ignored. Furthermore, Ng and Vogelsang (2002) demonstrate that inference based on the estimated VARs, forecasts and impulse response functions are generally invalid when mean shifts are omitted. They provide two choices: (i) remove the breaks before estimating the dynamic parameters, or (ii) estimate the mean shifts simultaneously with the autoregressive parameters. We choose the former as simulations in $\mathrm{Ng}$ and Vogelsang (2002) show that this is the preferred empirical approach when the level breaks in individual series do not coincide and when the breaks are so-called "additive outlier" type. The latter condition is already embedded in Bataa et al. (2014) procedure that we use. Blanchard and Quah (1989) and Gambe and Joutz (1993) also make the same choice.

Since our annual data span almost two hundred years, during which time potentially many structural changes and extreme events happened, it is necessary to consider the properties of each series ${ }^{2}$. To that end we use the univariate iterative testing procedure of Bataa et al. (2014), which decomposes observed variable $Y_{t}$ into components capturing level $\left(L_{t}\right)$, outliers $\left(O_{t}\right)$ and dynamics $\left(y_{t}\right)$ using

$$
Y_{t}=L_{t}+O_{t}+y_{t}
$$

where structural breaks are permitted in all components (except $\left.O_{t}\right) . L_{t}$ models the mean which is allowed to change over time. Dynamics are captured through an AR model without an intercept, with breaks permitted, not only in the AR coefficients, but also in the disturbance variance. All breaks (level, dynamics and variance) can be at distinct points of time, and hence regimes are defined as specific to these individual components, while outliers are detected allowing for any mean shifts ${ }^{3}$. Formal testing is done in an iterative fashion and results are from the convergence of this procedure ${ }^{4}$. The procedure revealed outliers only in inflation;

\footnotetext{
${ }^{2}$ Unit root analysis that justifies using the interest rate in level and the RPI and the real GDP in log first difference has been carried out, allowing for level and trend breaks of unknown timing and number. These are available upon request from the authors.

${ }^{3}$ Our definition of an outlier is based on 5 times Interquartile Range (IQR) away from the median (after removing the mean breaks) as in Bataa et al. (2014). For robustness, we also tried 7 times IQR but the results did not change much.

${ }^{4}$ Empirical results are available upon request
} 
specifically two deflation outliers, dated at 1921 and 1922, which are related with the end of WWI and following the depression of 1919-1921.

The tests also indicate structural breaks in the mean of the short-rate and inflation series. Therefore, we take out 3 "local" means from the short-rate (1820-1930, 1931-1950, 1951-2014) and 2 "local" means from the inflation rate (1820-1913 and 1914-2014) and these are shown along with their $90 \%$ confidence intervals in Figure $1^{5}$. Since there is no mean break in the growth rate we remove its whole sample mean before our multivariate analysis. Thus our multivariate analysis is based on series which have had outliers and mean breaks removed to alleviate the econometric concerns raised by Lutkepohl (1989), Ng and Vogelsang (2002) and Lettau and van Nieuwerburgh (2008).

\section{Multivariate analysis}

We use the generalized VAR methodology of Koop, Pesaran and Potter (1996) and Pesaran and Shin (1998), the forecast error variance decomposition (FEVD) analysis of which was recently updated in Diebold and Yilmaz $(2009,2012,2014)$. Given our data are annual and cover a long time span it is important to allow for correlated shocks. We rely on both the generalized impulse responses (GIRF) and the generalized forecast error variance decomposition (GFEVD) to derive relationship between growth, inflation and interest rates that is not sensitive to variable ordering. However, for comparison purposes, we also provide IRF results for the orthogonalized VAR using contemporaneous ordering restrictions (Cholesky decomposition), in which the real growth rate is ordered first, followed by the inflation and then the short rate; we refer to these as Cholesky or orthogonalized IRFs.

Let us consider the following conventional VAR system for $n$ demeaned variables:

$$
\mathbf{y}_{t}=\sum_{i=1}^{p} \boldsymbol{\Phi}_{i} \mathbf{y}_{t-i}+\mathbf{u}_{t}
$$

where $\mathbf{y}_{t}$ is a vector of stationary annual series. The error term $\mathbf{u}_{t}$ in (2) has mean zero and covariance matrix $E\left(\mathbf{u}_{t} \mathbf{u}_{t}^{\prime}\right)=\boldsymbol{\Sigma}$, and is temporally uncorrelated. The corresponding moving

\footnotetext{
${ }^{5}$ The averages within these sub-periods are $3.27 \%, 0.52 \%$ and $5.92 \%$ for the short rate and $-0.11 \%$ and $5.02 \%$ for the inflation. If the breaks are ignored, the whole sample averages are $3.86 \%$ and $2.54 \%$ for the short rate and the inflation, respectively. The whole sample average growth rate is $2.07 \%$.
} 
average form is

$$
\mathbf{y}_{t}=\sum_{i=0}^{\infty} \mathbf{A}_{i} \mathbf{u}_{t-i}
$$

We can obtain the generalized impulse response function of the one standard deviation shock by

$$
\psi_{j}(H)=\sigma_{j j}^{-0.5} \mathbf{A}_{H} \boldsymbol{\Sigma} \mathbf{e}_{j}, \quad H=0,1,2 \ldots
$$

where $\sigma_{j j}$ is $j^{\text {th }}$ residual variance, and $\mathbf{e}_{j}$ is a selection vector with unity in the $j^{\text {th }}$ element and zero otherwise.

This GIRF shows the effect of a shock to the $j^{(t h)}$ element of $\mathbf{y}_{t}$, equal to one percentage in magnitude, on the vector $\mathbf{y}_{t+H}$ for $H=0,1, \ldots$

The variance decomposition that allows to assess the fraction of the $H$ step-ahead error variance in forecasting $y_{i}$ that is due to shocks to $y_{j}, \forall j \neq i$, for each $i$ is the following:

$$
\theta_{i j}(H)=\frac{\sigma_{j j}^{-1} \sum_{h=0}^{H-1}\left(\mathbf{e}_{i}^{\prime} \mathbf{A}_{h} \boldsymbol{\Sigma} \mathbf{e}_{j}\right)^{2}}{\sum_{h=0}^{H-1} \mathbf{e}_{i}^{\prime} \mathbf{A}_{h} \boldsymbol{\Sigma} \mathbf{A}_{h}^{\prime} \mathbf{e}_{i}} \quad H=1, \ldots
$$

Notice that $\boldsymbol{\Sigma}=\mathbf{D P D}$, where $\mathbf{D}$ is a diagonal matrix of standard deviations and $\mathbf{P}$ is a correlation matrix; thus both the volatility and the correlations of the VAR residuals play a role in calculation of the GIRF and GFEVD alongside the VAR parameters.

Based on the normalized version of above Diebold and Yilmaz (2009, 2012, 2014) define total, directional, bivariate and net spillover measures. Given that their spillover measures are already very popular we omit their details here.

Our main interest is to test the stability of the above model. If the parameter stability is rejected we would like to see the consequences of those changes in the GIRF, GFEVD and the spillover measures. Parameter instability could originate from those in $\mathbf{\Phi}_{i}$, and thus in $\mathbf{A}_{i}, \mathbf{D}$ and $\mathbf{P}$. Therefore we use Bataa, et al. (2013) iterative structural break testing method. Space considerations again preclude a discussion of their method here.

Bataa, et al. (2018) show the implications of structural breaks in these quantities for the generalized and orthogonalized impulse responses. Since conditional mean specification (VAR) can affect the estimations of the variance-covariance matrix, and ultimately the GFEVD and various spillover measures that are based on it, we also employ Bataa et al. (2013) methodology to test for and identify which of its individual elements are behind an identified break in $\boldsymbol{\Phi}_{i}$. 


\section{Testing for structural breaks}

This section first tests whether the parameters and the variance-covariance matrix of the VAR model are constant over time and considers the implications of that time-variation. In particular, subsection 4.1 examines possible structural changes in both the autoregressive parameters and the variance-covariance matrix of a VAR through Bataa et al.'s (2013) procedure, while subsections 4.2 and 4.3 identify the sources of these system-wide breaks.

\subsection{Breaks in the VAR}

Owing to the large number of autoregressive coefficients in the VAR, a maximum of three breaks is permitted $\left(M_{c}=3\right)$, with a minimum of $20 \%$ of the sample required in each regime while we allow for a maximum of eight breaks for the variance covariance matrix $\left(M_{v}=8\right.$ with $10 \%$ trimming). The estimation of the VAR with 2 lags, guided by the information criterion and to ensure absence of residual autocorrelation, implies that two years of data are 'lost', so that the sample period for estimation starts in 1823 .

The first column of Table 1 contains results for breaks in the autoregressive parameters of equation (2), while the second column is for the variance-covariance matrix. WDmax statistics indicate the null hypothesis of no break is rejected against an alternative of an unknown number of breaks, for both the autoregressive coefficients and the variance-covariance matrix. The sequential tests indicate that there are two autoregressive coefficient breaks and five variancecovariance breaks. The bottom part of the table reports the estimated break dates and their $90 \%$ confidence intervals. The bootstrap $p$-values underneath confirm these asymptotic inferences ${ }^{6}$.

Interestingly, even after removing the level shifts/low frequency movements, as discussed in Section 2, we find breaks in the dynamic relationships, i.e. in the VAR parameters. Shifts occur in 1916 and 1975. Thus, the outbreak of WWI, and the subsequent burst in both mean and volatility of inflation appears to have changed the dynamic relationship. The second break could be associated with two large oil shocks in the $1970 \mathrm{~s}^{7}$.

\footnotetext{
${ }^{6}$ It is reassuring that although we allowed for a maximum of 3 breaks in the VAR coefficient and 8 breaks in the variance covariance matrix we do not reach this limit. $20 \%$ and $10 \%$ trimmings used in this case implies 38 and 19 observations, respectively, have to lie between any two breaks. However none of the breaks are subject to this boundary problem, except the second covariance matrix break in 1869. Bataa et al.'s (2013) iterative procedure converges quickly, after just 3 iterations.

${ }^{7}$ When we use HQ to select the lag length this is estimated to be 1 . The identified break datas from this smaller model are 1913 and 1977 for the VAR coefficients and 1885, 1913, 1932, 1951 and 1990 for the variance covariance matrix. In fact, given the number of parameters is twice fever than $\operatorname{VAR}(2)$ the maximum number of breaks was set to 5 with $15 \%$ trimming, not 3 as in VAR(2). However, one lag was too short to take account of the whole dynamic structure: wild-bootstrapped $p$-value for the absence of $4^{\text {th }}$ order residual autocorrelation is
} 
The first covariance matrix break in 1850 very likely reflects a "revolution" in British free trade policy, such as the Repeal of the Corn Laws in 1846 (Irwin, 1988). In the subsequent years the UK enjoyed a period of historic stability (panel B of Table 3). The 1869 break could be associated with the US signal about future world monetary regime. The 1869 Public Credit Act of the US stated that bondholders who purchased bonds to help finance the Civil War (18611865) would be paid back in gold. Thus, the Law was an early indicator that the country was moving toward reinstating the gold standard. After this break the volatility of both inflation and short rate declined (panel B of Table 3). There are three breaks in the 20th Century, in 1914, 1951 and 1989. These appear to occur around the time of i) the outset of WWI and the collapse of the Gold Standard, ii) the end of uncertainty and volatility associated with world wars and marks the beginning of the post-WWII stability, and iii) the change in monetary policy towards inflation targeting, not only in the UK but also around the world. In terms of the final break, the UK formally adopted inflation targeting in 1992 following its withdrawal from the European exchange rate mechanism (ERM). However, it is argued that during the UKs participation in the ERM since 1990 there was more emphasis on managing inflation; the UK attempted to shadow the German Mark, which it could only do if its inflation rate was close to that in Germany. What is abundantly clear is that UK inflation since 1990 has been far lower than that which occurred during the 1970s and 1980s. It also become clear in the early 1990s that money supply targeting was no longer having the desired impact. In 1993, Alan Greenspan (US Federal Reserve Chairman) alluded to a structural change and told Congress: "The historical relationships between money and income, and between money and the price level have largely broken down, depriving the aggregates of much of their usefulness as guides to policy" 8 .

\subsection{Breaks in persistence and Granger causality}

Conditional on the VAR coefficient breaks in the earlier table, Panel A of Table 2 sheds more light on the origins of these breaks. Columns represent VAR equations. The first value (in bold) of each cell (in each column) reports the difference between the sum of the autoregressive coefficients after and before the break date, with this placed against the dates of the second

$7 \%$ for the model estimated using data 1822-1913 and $p$-value for the absence of $1^{\text {st }}$ order residual autocorrelation is $1.3 \%$ between 1914-1977. Thus we had to increase the lag order to 2 which helps remove all the evidence of residual autocorrelation.

${ }^{8}$ The Money Supply Fedpoint, Federal Reserve Bank of New York, January 2003. 
subsample used in the comparison. Subsamples are those implied by the estimated structural break dates of Table 1. The first value in each cell in panel B reports the sum of estimated coefficients over the indicated subsample. In both cases, the values below are bootstrap pvalues (expressed as percentages) for the null hypothesis that the corresponding true value is 0 . If an individual coefficient break is not significant at $15 \%$ in panel $\mathrm{A}$, the corresponding subsample coefficients are restricted to be equal in panel B. Two and one stars and a spade indicate significance at 5\%,10\% and $15 \%$ respectively using wild bootstrapped $p$-values.

We see that the persistence, defined as the sum of autoregressive coefficients, increases for all three series around WWI. The difference between the sum of autoregressive coefficient after and before 1916 is highly significant for short rate ( $p$-value of insignificance is $3.34 \%)$ and is significant at $10 \%$ for growth rate and inflation. Persistence becomes significant only after that break, as can be seen from Panel B. There is no statistically significant evidence that the persistence further changing in 1975 . This is in contrast to a large literature that documents a decline in inflation persistence in 1970s using monthly CPI (see e.g. Benati, 2008b, and Bataa, et al. 2013, 2014, among others).

In 1916 the way inflation is Granger-caused by growth changes, the causality becoming insignificant from being highly inflationary. There is no reverse Granger causality. Granger causality from the growth to the short rate loses significance between 1917 and 1975. The causality is very strong since then, perhaps reflecting an activist monetary policy aimed at supporting real economic growth. On the other hand, higher short rate always affects growth negatively. Short rate starts to Granger cause inflation since 1917. On the other hand there is quite strong evidence against inflation Granger causing short rate since $1976^{9}$.

\subsection{Breaks in volatility and correlation}

Table 3 identifies the origins of the covariance matrix breaks, whether they are from volatility and/or correlation, and provides corresponding subsample estimates. The values reported

\footnotetext{
${ }^{9}$ When we enforce all the coefficients break at the system-wide break dates the growth shows no persistence until as late as 1976 and only since then there is Granger causality from the short rate, although it is significant only at $10 \%$. This contradicts with the inference derived allowing for only significant breaks, where the growth persistence is detected earlier and the short rate always Granger causes it. Moreover, there is Granger causality from the short rate to the inflation since 1975, much later than in B. If one ignores all the breaks then firstly economically and statistically important persistence changes will also be ignored. Moreover, a strong Granger causality from the growth to the inflation prior to the WWI will be diluted. A period when growth did not Granger cause short rate will also be missed. Furthermore, the fact that short rate is caused by inflation between 1917 and 1975 will disappear. Finally, inflation will never be Granger caused by the short rate, which is hard to justify given the activist monetary policy in recent period.
} 
are the final ones computed in the respective general to specific procedures. Conditional on the significant correlation breaks the table also provides instantaneous causality test results. Individual VAR coefficient breaks that are significant at least at $15 \%$ are allowed to change while the others are estimated using the whole sample in estimating the VAR residuals and, subsequently, the variance covariance matrix.

The first column of panel A reports the significance of structural break tests for diagonal elements of the covariance matrix of the VAR (volatility) and the second column for off-diagonal elements i.e., the correlation matrix. Bootstrap $p$-values correspond to the test of no change over adjacent covariance matrix subsamples identified in Table 1, with the result placed against the dates of the covariance matrix break date.

There is overwhelming evidence that only the latest of the variance-covariance matrix breaks is not a volatility break. There is equally strong evidence that this 1989 break is an important correlation break while the 1914 correlation break is significant only at $10 \%{ }^{10}$. As for individual volatility breaks, only the latest joint volatility break has an origin in all three variables, while the remaining breaks are due to only some of the series.

Panels B and C show sub-sample estimates of residual standard deviations and correlations and those ignoring the breaks [in square brackets]. Between 1915 and 1951, a period that includes both world wars, growth and inflation are most volatile, but post war stability is remarkable (standard deviations are $1.66 \%$ and $2.21 \%$ respectively), even compared with their long term values $(2.57 \%$ and $2.85 \%)$. In contrast, short rate volatility almost doubles: standard deviation is $1.43 \%$ after 1951 compared to $0.71 \%$ immediately before it and $0.66 \%$ during the classical Gold Standard. It is very clear that correlations from 1990 onwards are very different and much higher than before. Correlation between growth and inflation more than doubles after 1990 and that of between growth rate and short rate triples. Most strikingly, the correlation between the short rate and inflation increases ten-fold from a very low base (from $3.1 \%$ to $47.2 \%)$ and is extremely high by historical standard (8.3\%).

\footnotetext{
${ }^{10} 1914$ break loses its $10 \%$ significance as a correlation break when Granger causality is imposed. It becomes impossible to make a clear-cut inference about the sources of the variance-covariance matrix if one unnecessarily splits the sample or ignores altogether important structural breaks in the VAR coefficients. It appears imposing constant VAR parameters results in more spurious correlation breaks than volatility breaks. Furthermore, imposing the Granger causality results also play role with respect to inferences about correlation breaks. Details are available from the authors upon request.
} 


\section{Results}

Here we consider the implications of the statistically significant structural breaks identified in the previous section for the impulse responses, for the forecast error variance decompositions and finally for the volatility spillovers in sections 5.1, 5.2 and 5.3 respectively. We also discuss what happens to these quantities if we ignore the VAR breaks. To facilitate comparisons, all results are expressed in percentage terms.

\section{$5.1 \quad$ Impulse responses}

A useful qualitative comparison is provided by the impulse responses computed across subsamples. What is allowed to change across subsamples is however important. In terms of the VAR coefficients we are going to be quite liberal and allow for breaks that are significant at 15\%. Concerning the five variance-covariance matrix breaks we are not considering 1989 as a volatility break, but it is the only correlation break, as discussed in the previous sub-section.

Figures 2-4 show generalized impulse responses of three variables over ten years after one standard deviation (SD) shock (see panel B of Table 3 for their sizes). Rows indicate the variables that respond to the shock. Dotted and dashed lines (in blue) with shaded confidence intervals assume parameter constancy. A response in solid (red) line with dotted confidence interval is specific to the sub-regime specified on the top, using the results in Tables 2 and 3. For each plot two-standard-deviation wide confidence interval is obtained using a recursive design wild bootstrap procedure. In Figures 3-4 IRFs are also provided from a Cholesky decomposition; for the variable ordered first in a VAR, the generalized and the orthogonalized IRFs are the same (Pesaran and Shin, 1998).

\subsubsection{Growth shock}

The first thing to note from Figure 2 is that a growth shock exhibits moderately strong cumulative impact on growth itself using the full-sample model with no breaks. However, the breaks result in important heterogeneity. The pre-WWI responses are weaker and the long-run effect is less than the initial shock due to the statistically insignificant growth persistence during this period. The responses follow a similar path to the full sample in the following two sub-periods, that include the Keynesian policy era, although the levels vary depending on the size of the shock. For the post-1975 period, the responses have a similar shape to the full sample one in the 
first couple of years (although the initial shock is smaller). From year 5 onwards however, there is a clear positive trend to the response; they also have wide confidence intervals and hence the estimated responses are not different to that of the full sample.

\section{[INSERT: FIGURE 2]}

Row 3 indicates that ignoring the breaks would lead to the conclusion that $2.5 \%$ growth shock results in $3 \%$ (cumulative) increase in the short rate, which is statistically significant, after 10 years as if caused by aggregate demand. However, accounting for structural breaks presents a rather different picture. There is a very weak response of short-term interest rates to growth shocks pre-1975 and any impact is primarily over years 1-5. Then, the responses are much more apparent post 1976, due to the VAR break in 1975 and a contemporaneous correlation break in 1989. The magnitude of the effect for 1990-2014 peaks at more than $10 \%$ in year 10 ; this indicates an average rise in the short rate of $1.2 \%$ for the first 5 years which declines to about an average of $0.8 \%$ for years $6-10$. This suggests that short rates are most responsive to growth shocks in the most recent sub-sample (1990-2014). This strong response is also somewhat surprising given that this period is mainly characterised by the Bank of England following an inflation targeting regime during which it is primarily supposed to be focusing on maintaining price stability rather than responding strongly to fluctuations in growth! However, we should note that it is plausible that this partly reflects the anticipated impact of a growth shock on inflation. Further, the latest sub-sample response is somewhat stronger but not significantly different from the 1976-1989 period suggesting that the responsiveness of interest rates to growth shocks has not increased dramatically since the $1970 \mathrm{~s}^{11}$.

\subsubsection{Inflation shock}

Figure 3 depicts IRFs to an inflation shock; panel A for the generalized and panel B for the orthogonalized IRFs, respectively. UK inflation shocks for the full sample or no-break model are quite persistent for the first five years but then have a modest additional impact beyond that, whatever panel one looks at. Prior to WWI however, there is lower inflation persistence, and thus inflation shocks have very little long-term effect on the price level, once the structural breaks are recognized. In the later sub-samples an inflation shock has a more persistent effect, especially during the interwar period. The post 1917 responses are not statistically different

\footnotetext{
${ }^{11}$ We do not discuss in detail the impact of a real growth shock on inflation since this is not a primary focus of the paper. However, real growth shocks have positive effects on inflation in general with demand-pull inflation evident in all sub-sample periods.
} 
from that of the full sample. This evidence corroborates the US results of Fuhrer and Moore (1995) that there is high inflation persistence post-WWII and we provide novel evidence from IRFs. Our results suggest that this high inflation persistence actually dates back to 1917 in the UK suggesting that it is apparent across different monetary regimes. Hence, our results broadly suggest that it is not a change in monetary regime that is the source of high inflation persistence.

The figure also shows that an inflation shock has a small impact on the short-term interest rate for the full sample period, especially immediately after the shock. This is true whether one uses generalized or orthogonalized shocks. In panel A, a $3.85 \%$ inflation shock leads to an cumulative increase in interest rate of less than $2 \%$ after 10 years. The response is much smaller than one would expect under the Fisher hypothesis where the effect should be 1:1 (if the shock were permanent). This appears to be consistent with prior literature that the interest rates response to inflation is less than unity (for example Mishkin, 1992; Evans and Lewis, 1995). This also suggests that this key monetary policy tool is not adjusting sufficiently to counteract the effect of inflation shocks since an interest rate response greater than unity would be necessary to induce a fall in inflation in the future. Finally, there are no statistically significant long-run effects in the UK which appears inconsistent with the post-war results of Rapach (2003) but consistent with money neutrality, this is evidenced by the stabilising of the cumulated response function of the interest rate at an approximately constant level in the later years and this not being statistically different from zero.

Crucially, the structural breaks result in key differences. While in the earlier period the response of interest rates to inflation is much weaker compared to that of the no-break model, for 1917-1975 period it is even negative. For 1990-2014, the response is not only of the anticipated sign but also the strongest; the cumulated response continues to rise throughout the sample period to reach about $10 \%$ by year 10 according to GIRF and $6 \%$ according to Cholesky. Thus, there is substantial adjustment of interest rates to inflation during this period. Nevertheless even during this time of money growth targeting (during the 1980s) and inflation targeting (from 1997) the response is less than a unity in the short-term. This seems rather surprising since one would expect the nominal interest rate would need to adjust by more than unity in order to counter-balance the effect of the inflation shock.

[INSERT: FIGURE 3]

What happens to the real growth following an inflation shock? Here we start having quali- 
tatively different results depending on whether we orthogonalize the shocks or allow them to be correlated. According to the no-break model in panel A, an immediate positive yet insignificant boost turns into negative impact after the shock. The confidence interval of the negative GIRF shows statistical significance. When one allows for the structural breaks, the GIRFs confidence intervals are much wider and hence the effects are insignificant in any sub-periods. Thus, at best, there is a modest impact on real growth from an inflation shock. This is another indication of money neutrality.

\subsubsection{Nominal short rate shock}

Figure 4 indicates that the UK short rate shocks for the full-sample model are rather persistent and the cumulated response in the short rate continues through until year 10; in other words, the interest rate remains above its pre-shock level even after 10 years. However, the short rate does gradually mean-revert, as the increase in the cumulative effect getting smaller as time progresses. The only consistent difference to this from the sub-samples is that prior to 1917, the effect of the shock is substantially weaker driven, as for the other variables, by the low persistence regime of the pre-WWI era (Table 2$)^{12}$.

A nominal short term rate shock has a negative effect on growth for the no-break model; the impact is statistically significant but of moderate magnitude. A $1.1 \%$ interest rate shock leads to a fall in output of about $0.75 \%$ (cumulative) over the first 3 years but dissipates slightly by year 10. This suggests that the effectiveness of this key monetary policy tool to stimulate economic activity is rather limited.

However, the sub-sample analysis reveals that this shock has a substantial impact on growth during the 1917-1951 and especially the 1952-1975 periods. Over 1952-1975, a 1.43\% interest rate shock leads to a total output loss of about $2 \%$ over the first 3 years and about $4 \%$ by the end of 10 years. Hence it appears that an interest rate shock has a permanent long-run impact upon the level of GDP during this period. In contrast, in the later part of our sample (1976-1989 and 1990-2014) there is very little evidence that a short rate shock has a negative effect on growth in the long-run. For 1976-1989 the GIRFs follow the full sample path for the first 2 years before dissipating to about zero by year 5 . For 1990-2014 the effects are statistically less significant independent of whether one uses generalized or orthogonalized shocks.

\footnotetext{
${ }^{12}$ Some effects are intensified under the GIRF compared to the Cholesky IRF suggesting the GIRF effect is reflecting the contremporaneous correlation of interest rate shock with growth and inflation with subsequent feedback to the interest rate.
} 
Overall these results are very important since they suggest that an interest rate shock has a weaker impact on growth over recent years (1990-2014) compared to other post-WWI periods. Hence, unexpected monetary policy shocks may be a blunter tool now for stimulating or constraining the economy than in the past. Further, it suggests that the perceived wisdom of a strong correlation of short-term interest rates with real output (e.g. Bernanke and Blinder, 1992; Estrella and Hardouvelis, 1991) does not hold over recent years. This also raises the question of which policy tools are there nowadays that will actually assist the Bank of England in prudently managing the domestic economy. The finding of no long-run effect of interest rate on growth seems consistent with Haug and Dewald (2011) who report money growth is unrelated to output growth at longer horizons.

Another issue is that for the majority of the 1990-2014 period the UK was following inflation targeting (or monetary growth targeting) and hence growth concerns should not have been forefront in policymakers minds. Nevertheless, we saw in Figure 2 that nominal interest rates respond to growth during all periods especially since the 1970s. Hence the evidence from Figure 4 suggests that if the interest rate was rising out of macroeconomic management concerns then it may not have been meeting its objectives of stabilising growth.

\section{[INSERT: FIGURE 4]}

We now turn to the impact of an interest rate shock on inflation. The conventional view is that a rise in interest rates leads to lower inflation, ceteris paribus. However, results from the no-break model show that a shock to the nominal short-term rate has a modest positive effect on inflation, which reaches a cumulative effect of $+2.5 \%$ after 3 years and then peaking at about $+3.5 \%$ by year 10 . This effect is statistically significant throughout the 10 -year horizon examined. While this result is contrary to theory, it is however, consistent with the price puzzle (Sims, 1992).

Nevertheless, once we allow for the structural changes in the model an interesting heterogeneity emerges. While for the pre-1917 sub-samples there is no significant effect except on impact, for post-1917 sub-samples there is a positive response of inflation to interest rate shocks for up to 10 years, except during a short period of 1976-1989. Hence, it appears that the same forces have been driving both the inflation and short-rate since 1917 and especially since 1990 . Once we impose the Cholesky ordering however, so that the short-rate shock cannot have an immediate impact on inflation, then the effect is statistically significant only during the 19521975 period. Our results are reasonably consistent with Hanson's (2004) US evidence on the 
price puzzle which suggests the price puzzle is concentrated in the 1959-1979 sub-period rather than post 1980. Our UK results suggest the price puzzle is also evident much earlier (during the 1917-1951 period). However, it is plausible as suggested by Balke and Emery (1994) the results reported are due to an insufficient adjustment of the short rate to high inflation. That is the movement in the nominal short rate may not have been sufficient to counteract the rise in inflation, in such a scenario the real interest rate will fall (not rise) which may help explain why inflation tends to increase rather than decrease following a nominal short rate rise.

\subsubsection{Summary of key IRF results}

The main findings of the IRF analysis, which are highlighted by comparing the no-breaks case to when structural change is modelled, isare as follows. Firstly, the short rate responds much more strongly to growth and inflation over recent years compared to the no-breaks case (or to the earlier sub-periods). This suggests that policymakers have been proactively adjusting interest rates in response to fluctuations in these key macroeconomic variables which could have helped promote stability across the UK economy. Secondly, short-term interest rate shocks over recent years have limited ability to moderate either growth or inflation. For example, the impact of a short-rate shock on growth is at best half the magnitude for the post 1990 period compared to the no-breaks case. Consequently, if policymakers wish to make a sudden intervention to stimulate the economy then they would either require a much larger adjustment in the short rate (compared to the no-break case or earlier periods) or consider using alternative monetary policy tools. A further finding of interest to economic historians or to policymakers should historic conditions occur again is that the price puzzle (a short rate shock leading to higher inflation) is strongly apparent in the UK prior to WWII. Our longer sample enables us to examine earlier periods and we document that the price puzzle very much exists in the UK over 1917-1951, which is much earlier than Hansons (2004) finding in the US over 1959-1979 ${ }^{13}$

\subsection{Forecast error variance decompositions}

A comparison of generalized forecast error variance decompositions (GFEVD) over sub-periods also sheds light on the changes in British economy over the last two hundred years.

Table 4 provides GFEVD for short and long horizons: $h=1$ and 4 years. The $i j^{\text {th }}$ entry

\footnotetext{
${ }^{13}$ Our results also demonstrate a price puzzle in the UK for 1952-1975 which is generally consistent with Hanson (2004) result for the US.
} 
of the upper-left $3 \times 3$ series submatrix gives the $i j^{\text {th }}$ pairwise directional connectedness; i.e., the percent of forecast error variance of series $i$ due to shocks from series $j$. They are allowed to be different over the sub-samples defined by the statistically significant structural breaks. If bootstrap one (two) standard deviation(s) wide confidence interval does not contain zero they are marked with $\left.{ }^{* * *}\right)$. The quantities estimated over the whole sample, ignoring the structural breaks are in square brackets. We consider movements of each variable in turn.

\subsubsection{Short-term volatility}

We start with our benchmark model with no breaks. The point estimates under $h=1$ suggests that growth shocks account for $98.9 \%$ of the future movement in growth whereas only $1.0 \%$ and $0.1 \%$ are from inflation and the short rate shocks, respectively. Using the two standard deviation confidence intervals, we cannot reject the null hypotheses that the growth shock accounts for $100 \%$ of the movement in growth, indicating that over the full sample period the evolution of growth volatility is almost entirely determined by shocks to growth itself.

The sub-period analysis for growth broadly supports the main findings of the full sample at the 1 year horizon except for the latest sub-period. For 1990-2014, there are a several pertinent differences. First, the amount attributable to the growth shock falls substantially to $70.5 \%$. Second, the amount attributable to inflation increases to $9.7 \%$, which is higher than that from other sub-periods $(2.1 \%)$ and the full-sample (1.0\%), nevertheless none of these are statistically significant at 5\%. Thirdly, the variance attributable to the short rate is tiny pre-1990 $(0.4 \%)$ but rises dramatically to $19.8 \%$ post-1990 and becomes statistically significant.

Estimates for inflation at the one year horizon indicate that this is also primarily determined by shocks to itself. Point estimates are above $90 \%$ for the full sample and close to that for all sub-periods except 1990-2014. Growth shocks, perhaps surprisingly have very little effect on movements in inflation, at least initially; point estimates are never more than $2 \%$ and never statistically significant apart from during 1990-2014, when this rises to $7.3 \%$, but insignificant at $5 \%$. In contrast, short rate shocks do have an impact on inflation where the point estimates are always more than $8 \%$. Short rate shocks are statistically significant for the full-sample, as well as the sub-periods. Since 1990 the short rate shocks account for $39.6 \%$ of the movement in inflation.

As for the short rate, the deviations from the model forecast are also primarily determined by shocks to itself for the full sample and in almost all sub-periods. Point estimates are always 
above $90 \%$, with the exception of the 1990-2014 sub-sample. Growth shocks, again, have very little effect on movements in the short rate prior to 1990, with point estimates never higher than mere $0.5 \%$. In contrast, inflation shocks always have statistically significant impact on the short rate where point estimates are more than 8\%. Since 1990 inflation shocks can account for $36.8 \%$ of the movement in the short-rate, while growth shocks can account for $13.8 \%$.

\subsubsection{Long-term volatility}

The second column of each sub-section of Table 4 reports results for the 4-year forecast horizon $(h=4)$. Here are some important differences relative to the 1-year forecasts. In general, at the 4-year horizon, less of the variation is determined by the shocks to the variable itself; although there is more variation in sub-periods, the results for the 1990-2014 sub-period are typically amongst the lowest. For growth, shocks to growth itself explain above $90 \%$ of variance for the full-sample (declines from $98.9 \%$ at $h=1$ ). In most sub-periods the growth shocks explain more than $90 \%$ of the variance, although this is below $62 \%$ for 1851-1869, 1952-1975 and 1990-2014. These reductions are accompanied by an increase in importance of the short rate shocks; in fact, the short rate shocks explain more than $24 \%$ of the 4-year GFEVD for growth in each of these 3 sub-periods and these are significant at $5 \%$. In contrast, the contributions from inflation shocks are statistically significant only during the 1990-2014 sub-period, when they explain $17.4 \%$ of the growth variance. This suggests that for the recent period both short rate shocks and inflation shocks have important effects on growth and that the central bank should bear this in mind when formulating monetary policy.

As for the 4-year ahead inflation GFEVD, it has key differences relative to the 1-year horizon. First, less than $85 \%$ of the error variance is attributable to inflation shocks itself for the full sample as well as the sub-periods. The point estimates are even less than $50 \%$ for the $1952-1975$ and 1990-2014 periods. We can also now reject a hypothesis that none of the error variance is attributable to the short rate shocks since the beginning of the WWI and they can explain as high as $48.7 \%$ of variance. In contrast only prior to 1917, the growth shocks can explain more than 20\% (apart from 1851-1869, when it is 7.5\%). For 1990-2014, the shares of the inflation volatility by the short rate and the inflation shocks are almost the same. Thus, the short rate shocks are an increasingly important determinant of inflation volatility, and that monetary policymakers nowadays may be able to use the short rate to influence inflation. In contrast, prior to 1915 the short-rate had a very modest ability to explain inflation variability. [INSERT: 


\section{TABLE 4]}

At this long horizon, although no-break model indicates $79.4 \%$ of the short rate volatility is attributable to short rate shocks themselves, the structural break analysis indicates that such a high proportion has been observed only in 35 out of about 200 years history. The point estimates suggest that the proportion has decreased by more than a half to $41.1 \%$ in the 1990 2014 period from its peak in 1952-1975. This seems to suggest in general that the short rate in the medium term is responsive to both growth rate and inflation shocks. Even during the 1990-2014 sub-sample, when the central bank is supposed to have been following an inflation targeting (or money growth targeting) policy, it seems that the short rate has been responding almost equally to both of these shocks.

\subsection{Volatility spillovers and Summary}

Here we provide various connectedness measures based on GFEVD following the approach of Diebold and Yilmaz $(2009,2012,2014)$. Previously, this method has been primarily applied to higher frequency, high mean reversion data and hence our application to lower frequency, low mean reversion series is somewhat novel; the method can be appropriately applied to any stationary series ${ }^{14}$. The final two columns of Table 4 report the volatility spillovers from other variables to the variable in the row-panel. For example, for growth at the 1-year horizon mere $1.1 \%$ of the forecast error variance is attributable to spillovers from the other two variables if one ignores the breaks. However, for the 1990-2014 sub-period it is as high as $29.5 \%$, demonstrating much larger volatility spillovers to the growth in recent years. At this horizon, a similar pattern is also apparent for inflation and short rate; in general about $10 \%$ of error variance is attributable to spillovers but this rises to about 50\% for 1990-2014.

The "To others" row-panel gives the volatility spillovers from the variable of interest to others. At 1-year horizon, the spillovers greatly increased post-1990 for all the variables. Volatility spillovers increase from less than 3\% before 1990 to at least $20 \%$ afterwards. The "Net" rows give the difference between the "To others" and "From others" segments. In general, these values are very close to each other for the 1-year horizon forecast errors, except for the 1990-2014 sub-period. During the latest sub-period it seems as if there are substantially higher spillovers

\footnotetext{
${ }^{14}$ We follow Diebold and Yilmaz $(2009,2012,2014)$ and calculate the directional spillovers using the normalized elements of the generalized variance decomposition matrix so that rows sum to $100 \%$. There is not much movement after 4 years of the shock and essentially converges. A table that relies on the Cholseky orthogonalization is available from the authors upon request and is omitted here to conserve space.
} 
(almost 9\%) given to other variables by the short rate than those received from other variables. This is primarily offset by growth giving substantially lower spillovers to other variables than it received. At 4-year horizon, the volatility spillovers to others are much higher than those of the short horizon, and the later sub-periods have more spillovers than earlier.

The "Bi-variate" rows indicate that there is virtually no volatility spillover at 1 year horizon to the growth from either the short rate or the inflation up until 1990 when the spillover becomes significant. The net bi-variate volatility spillover is from the short rate to the inflation and again this becomes significant only since 1990 (at 10\%). These changes are in contrast to the constant parameter model inferences reported in square brackets.

The total spillover index is $5.7 \%$ if one ignores all the VAR coefficient and covariance matrix breaks but significantly rises to $42.3 \%$ for $1990-2014$; this indicates that there were generally very modest spillovers for the full sample but very substantial spillover over recent years. Therefore, these variables are much more inter-connected nowadays and policy-makers should take this into account when implementing macroeconomic management strategies.

These results suggest that while spillover effects pre-1990 depend upon the variables and the sub-periods examined, those in the post-1990 period are consistently larger than before. This broadly complements findings from the IRF analysis that the short rate is responding more to growth and inflation since 1990. Therefore, the clear interconnectedness between our key economic variables is only a recent phenomenon in the context of about 200 years of history. Since 1990, there is strong connectedness apparent at a 1 year horizon which suggests that the speed of transmission between these key variables is quicker nowadays than at any time in the last 200 years. Consequently, given that the 1990 structural change is in correlations then this also suggests that policymakers should be vigilant for future changes in correlations since these would potentially substantially impact the connectedness of these key macroeconomic variables.

\section{Conclusions}

The main objective of this paper is to model the dynamic behavior of the short-term interest rate, inflation and economic growth over the period 1820-2014 for the United Kingdom. Initially we examine if there are structural breaks (of persistence, mean or volatility) in individual series using the iterative procedure that was recently developed by Bataa, et al. (2014). We then identify, in a multivariate context, if there has been any structural breaks in the relationship 
between these variables using a vector autoregressive (VAR) model.

Our primary empirical analysis employs the generalized VAR methodology of Koop, Pesaran and Potter (1996) and Pesaran and Shin (1998), the forecast error variance decomposition analysis of which is updated in Diebold and Yilmaz $(2009,2012,2014)$. This is because our data frequency is annual and covers an extended time span; it is important to allow for correlated shocks in this context. We rely on generalized versions of the impulse responses and the forecast error variance decompositions that are not sensitive to variable ordering but provide results from Cholesky decomposition for robustness.

For our multivariate analysis we use the methodology of Bataa, et al. (2013). The main innovation of their methodology is that it allows for changes in both the VAR parameters as well as the variance covariance matrix, but not necessarily at the same time, a feature that is vital when taking a long-term perspective. Then we examine if each structural break is the result of a change in persistence, a break in Granger causality, a shift in volatility or a change in correlation. Indeed, we find that one or a combination of these sources are behind the structural breaks in a trivariate VAR of short term interest rates, inflation and growth.

Most covariance matrix breaks can be primarily attributed to changes in volatility, although these mainly occur prior to the end of WWI. We also find that prior to WWI that the interrelationships between the three variables were weak compared to recent decades as highlighted by the IRFs. This appears due to a structural break in the persistence of all three variables in 1917 (when persistence increased) and also from a volatility break in the covariance matrix (volatility increased). There is also very strong evidence that the dynamic relationship between inflation and the short rate breaks down during the Great War; there is some evidence Granger causality from the growth rate to the short rate also changed during this period. Our results confirm earlier research that a great moderation occurred but suggests that the structural change is apparent by 1952 in UK annual data. We do find a covariance matrix break in 1989 but this can be attributed to a break in correlation rather than a break in volatility. The finding that there has been no significant structural break in the correlation between the short term interest rate, inflation and growth until 1989 is indeed one of the most interesting.

A key finding from our analysis is that the dynamic behaviour of our variables of interest have been distinctly different in recent decades compared to earlier sub-samples. Prior to WWI the interrelationships between the three key variables of interest were weak, however this has changed for recent decades. We find that the short rate responds strongly to both growth post- 
1975 and to inflation since at least 1990. However, short rate shocks do not have significant negative impacts either upon the growth rate or inflation over recent years. The implication is that the effectiveness and role of the short term interest rate shocks as a tool for policymakers may need to be reconsidered. This is because empirical results for the UK indicate that a very large change in interest rate would be necessary for there to be a substantial impact on growth or on inflation. Given the 1990 break is related to a shift in correlations amongst these key variables it suggests that policymakers should watch out for developments that could impact these correlations in the future; correlation breaks could potentially substantially change the magnitude of the effect of interest rate shocks upon growth or inflation. Consequently, economic policymakers need to carefully monitor the linkages between these variables and be prepared to adjust the way monetary tools are used when faced with structural change. 
TABLE 1. ITERATIVE STRUCTURAL BREAK TEST RESULTS

\begin{tabular}{|c|c|}
\hline VAR Coefficients & Covariance matrix \\
\hline \multicolumn{2}{|c|}{ Asymptotic WDmax test statistics [and critical values] } \\
\hline $232 . \overline{86^{* *}[42.63]}$ & $77.97^{* *}[22.59]$ \\
\hline \multicolumn{2}{|c|}{ Asymptotic sequential test statistics [and critical values] } \\
\hline $101.15^{* *}[41.93]$ & $36.57^{* *}[23.23]$ \\
\hline \multirow[t]{4}{*}{$19.73 \quad[43.72]$} & $29.26^{* *}[24.15]$ \\
\hline & $32.84^{* *}[24.77]$ \\
\hline & $25.98^{* *}[25.26]$ \\
\hline & $13.54 \quad[25.70]$ \\
\hline \multicolumn{2}{|c|}{ Break dates, confidence intervals (and bootstrap p-values) } \\
\hline & $\mathbf{1 8 5 0}[1849-1851]$ \\
\hline & $(0.00)$ \\
\hline & $1869[1866-1870]$ \\
\hline & $(0.01)$ \\
\hline $1916[1909-1921]$ & $1914[1913-1929]$ \\
\hline$(0.04)$ & $(0.05)$ \\
\hline & $1951[1949-1952]$ \\
\hline & $(0.00)$ \\
\hline $1975[1971-1978]$ & $1989[1972-1990]$ \\
\hline$(1.07)$ & $(1.88)$ \\
\hline
\end{tabular}

Notes: Values are reported are at convergence of the iterative procedure of Bataa, et al. (2013). The WDmax test examines the null hypothesis of no break against an unknown number of breaks, to a maximum number of breaks ( 3 for VAR coefficients and 8 for variance-covariance matrix). If the overall statistic is significant at $5 \%$, sequential tests are applied starting with the null hypothesis of one break and continuing until the relevant statistic is not significant. Asymptotic critical values for the $5 \%$ significance level are reported [in square brackets] and $* *$ indicates the statistic is significant at this level. The estimated break dates and their $90 \%$ confidence intervals [in square brackets] are also reported. Bootstrap p-values corresponding to the null hypothesis that a break that is asymptotically significant is actually not are also reported in brackets.

TABLE 2. INDIVIDUAL COEFFICIENT BREAKS AND GRANGER CAUSALITY

\begin{tabular}{|c|c|c|c|c|c|c|c|}
\hline \multirow[b]{2}{*}{ Subsample } & \multirow[b]{2}{*}{$\begin{array}{l}\text { Explana- } \\
\text { tory }\end{array}$} & \multicolumn{3}{|c|}{$\frac{\text { A. Coefficient Break Tests }}{\text { Dependent variable }}$} & \multicolumn{3}{|c|}{$\frac{\text { B. Estimated Coefficients }}{\text { Dependent variable }}$} \\
\hline & & Growth & Inflation & $\begin{array}{l}\text { Short } \\
\text { rate }\end{array}$ & Growth & Inflation & Short rate \\
\hline \multirow[t]{2}{*}{$1823-1916$} & Growth & & & & -0.15 & $0.66^{* *}$ & $0.20^{* *}$ \\
\hline & & & & & 31.02 & 0.03 & 0.10 \\
\hline \multirow[t]{2}{*}{$1917-1975$} & & $0.61^{*}$ & $-0.49 * *$ & $-0.12^{\infty}$ & $0.39 * *$ & 0.19 & 0.08 \\
\hline & & 8.62 & 2.58 & 13.97 & 0.79 & 84.26 & 10.26 \\
\hline \multirow[t]{2}{*}{$1976-2014$} & & 0.06 & -0.06 & $0.55^{* *}$ & & & $0.55^{* *}$ \\
\hline & & 32.69 & 67.37 & 1.97 & & & 1.01 \\
\hline \multirow[t]{2}{*}{$1823-1916$} & Inflation & & & & -0.07 & 0.34 & 0.08 \\
\hline & & & & & 89.30 & 14.12 & 10.88 \\
\hline \multirow[t]{2}{*}{$1917-1975$} & & -0.06 & $0.43^{*}$ & $-0.10^{* *}$ & & $0.76^{* *}$ & $-0.02^{*}$ \\
\hline & & 60.11 & 8.41 & 0.46 & & 0.00 & 9.30 \\
\hline \multirow[t]{2}{*}{$1976-2014$} & & 0.14 & -0.04 & $0.15^{\infty}$ & & & 0.12 \\
\hline & & 50.72 & 58.07 & 14.52 & & & 44.71 \\
\hline \multirow[t]{2}{*}{$1823-1916$} & Short & & & & $-0.24^{* *}$ & 0.07 & 0.50 \\
\hline & rate & & & & 3.85 & 22.12 & 19.96 \\
\hline \multirow[t]{2}{*}{$1917-1975$} & & 0.15 & $0.21^{* *}$ & $0.31^{* *}$ & & $0.13^{* *}$ & $0.81^{* *}$ \\
\hline & & 21.37 & 1.60 & 3.34 & & 2.58 & 0.00 \\
\hline \multirow[t]{2}{*}{$1976-2014$} & & 0.31 & -0.34 & -0.01 & & & \\
\hline & & 16.70 & 36.63 & 52.64 & & & \\
\hline
\end{tabular}

Notes: Columns represent equations. The first value (in bold) of each cell in panel A reports the difference between the sum of relevant coefficients after and before the break date, with this placed against the dates of the second subsample used in the comparison. The first value in each cell in panel B reports the estimated coefficients over the indicated subsample. In both cases, the values below are bootstrap p-values (expressed as percentages) for the null hypothesis that the coefficients are equal to 0 . If an individual coefficient break is not significant at $15 \%$ in panel A, the corresponding subsample coefficients are restricted to be equal in panel B. Subsamples are those implied by the estimated structural break dates of Table 2 . Significant at $* * 5 \%, * 10 \%,{ }^{\star} 15 \%$, using wild bootstrap p-value. 


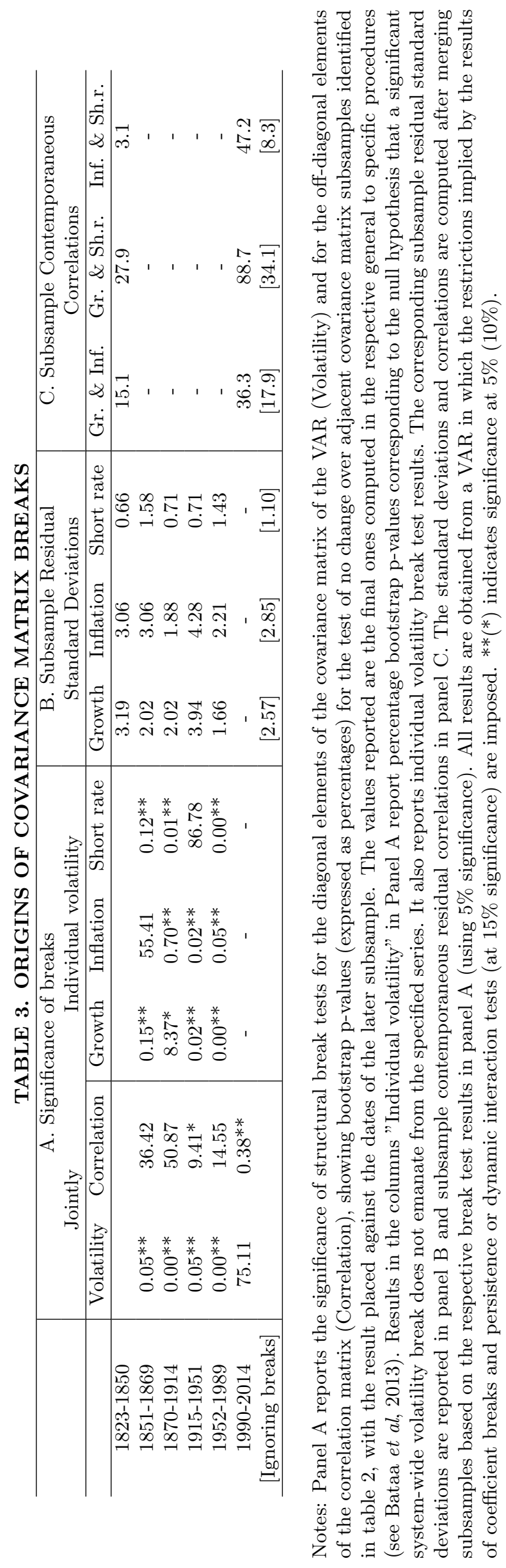


TABLE 4. GENERALIZED FEVD AND SPILLOVERS

\begin{tabular}{|c|c|c|c|c|c|c|c|c|c|}
\hline \multirow[t]{2}{*}{ Series } & \multirow[t]{2}{*}{ Regimes } & \multicolumn{2}{|c|}{ Growth shock } & \multicolumn{2}{|c|}{ Inflation shock } & \multicolumn{2}{|c|}{ Short rate shock } & \multicolumn{2}{|c|}{ From others } \\
\hline & & $h=1$ & $h=4$ & $h=1$ & $h=4$ & $h=1$ & $h=4$ & $h=1$ & $h=4$ \\
\hline \multirow[t]{9}{*}{ Growth } & $1823-1850$ & $97.5^{* *}$ & $94.2^{* *}$ & 2.1 & $3.8^{*}$ & 0.4 & $2.1^{*}$ & 2.5 & $5.8^{*}$ \\
\hline & $1851-1869$ & $97.5^{* *}$ & $61.4^{* *}$ & 2.1 & $11.1^{*}$ & 0.4 & $27.4^{* *}$ & 2.5 & $38.6^{* *}$ \\
\hline & $1870-1914$ & $97.5^{* *}$ & $92.6^{* *}$ & 2.1 & $3.9^{*}$ & 0.4 & $3.5^{*}$ & 2.5 & $7.4^{*}$ \\
\hline & $1915-1916$ & $97.5^{* *}$ & $93.8^{* *}$ & 2.1 & $4.2^{*}$ & 0.4 & $2.0^{*}$ & 2.5 & $6.2^{*}$ \\
\hline & $1917-1951$ & $97.5^{* *}$ & $94.6^{* *}$ & 2.1 & 2.2 & 0.4 & $3.2^{*}$ & 2.5 & $5.4^{*}$ \\
\hline & $1952-1975$ & $97.5^{* *}$ & $55.1^{* *}$ & 2.1 & $5.5^{*}$ & 0.4 & $39.4^{* *}$ & 2.5 & $44.9^{* *}$ \\
\hline & 1976-1989 & $97.5^{* *}$ & $77.6^{* *}$ & 2.1 & $7.2^{*}$ & 0.4 & $15.2^{*}$ & 2.5 & $22.4^{* *}$ \\
\hline & $1990-2014$ & $70.5^{* *}$ & $58.2^{* *}$ & $9.7^{*}$ & $17.4^{* *}$ & $19.8^{* *}$ & $24.4^{* *}$ & $29.5^{* *}$ & $41.8^{* *}$ \\
\hline & [Ignoring breaks] & {$\left[98.9^{* *}\right]$} & {$\left[90.6^{* *}\right]$} & {$[1.0]$} & {$\left[4.0^{*}\right]$} & {$[0.1]$} & {$\left[5.4^{*}\right]$} & {$[1.1]$} & {$\left[9.4^{*}\right]$} \\
\hline \multirow[t]{9}{*}{ Inflation } & $1823-1850$ & 1.9 & $27.5^{* *}$ & $89.8^{* *}$ & $67.4^{* *}$ & $8.3^{* *}$ & $5.1^{*}$ & $10.2^{* *}$ & $32.6^{* *}$ \\
\hline & $1851-1869$ & 1.9 & $7.5^{*}$ & $89.8^{* *}$ & $84.6^{* *}$ & $8.3^{* *}$ & $7.9^{*}$ & $10.2^{* *}$ & $15.4^{* *}$ \\
\hline & 1870-1914 & 1.9 & $29.6^{* *}$ & $89.8^{* *}$ & $65.4^{* *}$ & $8.3^{* *}$ & $4.9^{*}$ & $10.2^{* *}$ & $34.6^{* *}$ \\
\hline & $1915-1916$ & 1.9 & $22.3^{* *}$ & $89.8^{* *}$ & $72.1^{* *}$ & $8.3^{* *}$ & $5.6^{* *}$ & $10.2^{* *}$ & $27.9^{* *}$ \\
\hline & 1917-1951 & 1.9 & $9.0^{*}$ & $89.8^{* *}$ & $72.6^{* *}$ & $8.3^{* *}$ & $18.4^{* *}$ & $10.2^{* *}$ & $27.4^{* *}$ \\
\hline & $1952-1975$ & 1.9 & 3.8 & $89.8^{* *}$ & $47.4^{* *}$ & $8.3^{* *}$ & $48.7^{* *}$ & $10.2^{* *}$ & $52.6^{* *}$ \\
\hline & 1976-1989 & 1.9 & $9.0^{*}$ & $89.8^{* *}$ & $76.2^{* *}$ & $8.3^{* *}$ & $14.8^{* *}$ & $10.2^{* *}$ & $23.8^{* *}$ \\
\hline & $1990-2014$ & $7.3^{*}$ & $12.9^{*}$ & $53.1^{* *}$ & $47.3^{* *}$ & $39.6^{* *}$ & $39.8^{* *}$ & $46.9^{* *}$ & $52.7^{* *}$ \\
\hline & [Ignoring breaks] & {$[0.9]$} & {$\left[7.7^{*}\right]$} & {$\left[91.6^{* *}\right]$} & {$\left[82.6^{* *}\right]$} & {$\left[7.6^{* *}\right]$} & {$\left[9.7^{* *}\right]$} & {$\left[8.4^{* *}\right]$} & {$\left[17.4^{* *}\right]$} \\
\hline \multirow[t]{9}{*}{ Short rate } & $1823-1850$ & 0.4 & $37.9^{* *}$ & $8.4^{* *}$ & $18.8^{* *}$ & $91.2^{* *}$ & $43.3^{* *}$ & $8.8^{* *}$ & $56.7^{* *}$ \\
\hline & $1851-1869$ & 0.4 & $3.9^{*}$ & $8.4^{* *}$ & $14.6^{* *}$ & $91.2^{* *}$ & $81.5^{* *}$ & $8.8^{* *}$ & $18.5^{* *}$ \\
\hline & $1870-1914$ & 0.4 & $25.7^{* *}$ & $8.4^{* *}$ & $15.8^{* *}$ & $91.2^{* *}$ & $58.6^{* *}$ & $8.8^{* *}$ & $41.4^{* *}$ \\
\hline & $1915-1916$ & 0.4 & $38.6^{* *}$ & $8.4^{* *}$ & $21.9^{* *}$ & $91.2^{* *}$ & $39.5^{* *}$ & $8.8^{* *}$ & $60.5^{* *}$ \\
\hline & 1917-1951 & 0.4 & $15.0^{*}$ & $8.4^{* *}$ & 7.9 & $91.2^{* *}$ & $77.1^{* *}$ & $8.8^{* *}$ & $22.9^{*}$ \\
\hline & $1952-1975$ & 0.4 & 1.4 & $8.4^{* *}$ & $5.1^{*}$ & $91.2^{* *}$ & $93.5^{* *}$ & $8.8^{* *}$ & $6.5^{*}$ \\
\hline & 1976-1989 & 0.4 & $28.2^{* *}$ & $8.4^{* *}$ & $16.6^{* *}$ & $91.2^{* *}$ & $55.2^{* *}$ & $8.8^{* *}$ & $44.8^{* *}$ \\
\hline & $1990-2014$ & $13.8^{*}$ & $28.1^{* *}$ & $36.8^{* *}$ & $30.9^{* *}$ & $49.4^{* *}$ & $41.1^{* *}$ & $50.6^{* *}$ & $58.9^{* *}$ \\
\hline & [Ignoring breaks] & {$[0.1]$} & {$\left[11.6^{* *}\right]$} & {$\left[7.6^{* *}\right]$} & {$\left[9.0^{* *}\right]$} & {$\left[92.3^{* *}\right]$} & {$\left[79.4^{* *}\right]$} & {$\left[7.7^{* *}\right]$} & {$\left[20.6^{* *}\right]$} \\
\hline \multirow[t]{9}{*}{ To others } & $1823-1850$ & 2.3 & $65.4^{* *}$ & $10.5^{* *}$ & $22.6^{* *}$ & $8.7^{* *}$ & $7.1^{*}$ & & \\
\hline & $1851-1869$ & 2.3 & $11.4^{*}$ & $10.5^{* *}$ & $25.7^{* *}$ & $8.7^{* *}$ & $35.3^{* *}$ & & \\
\hline & $1870-1914$ & 2.3 & $55.3^{* *}$ & $10.5^{* *}$ & $19.6^{* *}$ & $8.7^{* *}$ & $8.4^{*}$ & & \\
\hline & $1915-1916$ & 2.3 & $60.9^{* *}$ & $10.5^{* *}$ & $26.1^{* *}$ & $8.7^{* *}$ & $7.6^{* *}$ & & \\
\hline & $1917-1951$ & 2.3 & $24.0^{*}$ & $10.5^{* *}$ & $10.1^{*}$ & $8.7^{* *}$ & $21.6^{* *}$ & & \\
\hline & $1952-1975$ & 2.3 & 5.2 & $10.5^{* *}$ & $10.7^{*}$ & $8.7^{* *}$ & $88.2^{* *}$ & & \\
\hline & 1976-1989 & 2.3 & $37.2^{* *}$ & $10.5^{* *}$ & $23.9^{* *}$ & $8.7^{* *}$ & $30.0^{* *}$ & & \\
\hline & $1990-2014$ & $21.2^{*}$ & $40.9^{* *}$ & $46.5^{* *}$ & $48.2^{* *}$ & $59.3^{* *}$ & $64.3^{* *}$ & & \\
\hline & [Ignoring breaks] & {$[1.0]$} & {$\left[19.3^{* *}\right]$} & {$\left[8.6^{* *}\right]$} & {$\left[13.0^{* *}\right]$} & {$\left[7.6^{* *}\right]$} & {$\left[15.0^{* *}\right]$} & & \\
\hline \multirow[t]{9}{*}{ Net } & $1823-1850$ & -0.2 & $59.6^{* *}$ & 0.3 & -10.0 & -0.1 & $-49.6^{* *}$ & & \\
\hline & $1851-1869$ & -0.2 & $-27.1^{*}$ & 0.3 & 10.3 & -0.1 & 16.8 & & \\
\hline & $1870-1914$ & -0.2 & $48.0^{* *}$ & 0.3 & $-15.0^{*}$ & -0.1 & $-33.0^{* *}$ & & \\
\hline & 1915-1916 & -0.2 & $54.7 * *$ & 0.3 & -1.8 & -0.1 & $-52.9^{* *}$ & & \\
\hline & $1917-1951$ & -0.2 & $18.6^{*}$ & 0.3 & $-17.3^{*}$ & -0.1 & -1.3 & & \\
\hline & $1952-1975$ & -0.2 & $-39.7^{* *}$ & 0.3 & $-41.9 * *$ & -0.1 & $81.6^{* *}$ & & \\
\hline & 1976-1989 & -0.2 & 14.8 & 0.3 & 0.1 & -0.1 & -14.9 & & \\
\hline & $1990-2014$ & $-8.3^{* *}$ & -0.9 & -0.4 & -4.5 & $8.7^{* *}$ & 5.3 & & \\
\hline & [Ignoring breaks] & {$[-0.1]$} & {$[10.0]$} & {$[0.1]$} & {$[-4.4]$} & {$[-0.1]$} & {$[-5.5]$} & & \\
\hline \multicolumn{2}{|c|}{ Bi-variate } & \multicolumn{2}{|c|}{ Growth \& Inflation } & \multicolumn{2}{|c|}{ Growth \& Short rate } & \multicolumn{2}{|c|}{ Inflation \& Short rate } & \multicolumn{2}{|c|}{ Index } \\
\hline & $1823-1850$ & 0.2 & $-23.7^{* *}$ & 0.0 & $-35.8^{* *}$ & -0.1 & $-13.8^{*}$ & $7.2^{* *}$ & $31.7^{* *}$ \\
\hline & 1851-1869 & 0.2 & 3.6 & 0.0 & $23.5^{*}$ & -0.1 & -6.7 & $7.2^{* *}$ & $24.2^{* *}$ \\
\hline & $1870-1914$ & 0.2 & $-25.8^{* *}$ & 0.0 & $-22.2^{* *}$ & -0.1 & $-10.8^{*}$ & $7.2^{* *}$ & $27.8^{* *}$ \\
\hline & $1915-1916$ & 0.2 & $-18.1^{*}$ & 0.0 & $-36.6^{* *}$ & -0.1 & $-16.3^{*}$ & $7.2^{* *}$ & $31.5^{* *}$ \\
\hline & $1917-1951$ & 0.2 & -6.8 & 0.0 & -11.8 & -0.1 & 10.5 & $7.2^{* *}$ & $18.6^{* *}$ \\
\hline & $1952-1975$ & 0.2 & 1.7 & 0.0 & $38.0^{* *}$ & -0.1 & $43.6^{* *}$ & $7.2^{* *}$ & $34.7^{* *}$ \\
\hline & 1976-1989 & 0.2 & -1.8 & 0.0 & -13.0 & -0.1 & -1.9 & $7.2^{* *}$ & $30.3^{* *}$ \\
\hline & $1990-2014$ & $2.4^{* *}$ & 4.5 & $5.9^{* *}$ & -3.6 & $2.8^{*}$ & $9.0^{*}$ & $42.3^{* *}$ & $51.1^{* *}$ \\
\hline & [Ignoring breaks] & {$[0.1]$} & {$[-3.7]$} & {$[0.0]$} & {$[-6.2]$} & {$[-0.1]$} & {$[0.7]$} & {$\left[5.7^{* *}\right]$} & {$\left[15.8^{* *}\right]$} \\
\hline
\end{tabular}

Notes: Connectedness table for two horizons: $h=1,4$. The $i j^{\text {th }}$ entry of the upper-left $3 \times 3$ series submatrix gives the $i j^{t h}$ pairwise directional connectedness; i.e., the percent of forecast error variance of series $i$ due to shocks from series $j$. They are allowed to be different over the sub-samples defined by the statistically significant structural breaks. If bootstrap one (two) standard deviation(s) wide confidence interval does not contain zero they are marked with $*(* *)$. The quantities estimated over the whole sample, ignoring the structural breaks are in square brackets. The rightmost (From others) column gives total directional connectedness (from); i.e., row sums (from all others to $i$ ). The bottom (To others) row gives total directional connectedness (to); i.e., column sums (to all others from $j$ ). Next (Net) row gives the difference in total directional connectedness (to-from). The bottom-right numbers are total connectedness (mean 'from' connectedness, or equivalently, mean 'to' connectedness). The bottommost row also gives bi-variate spillovers. 
a) Short rate
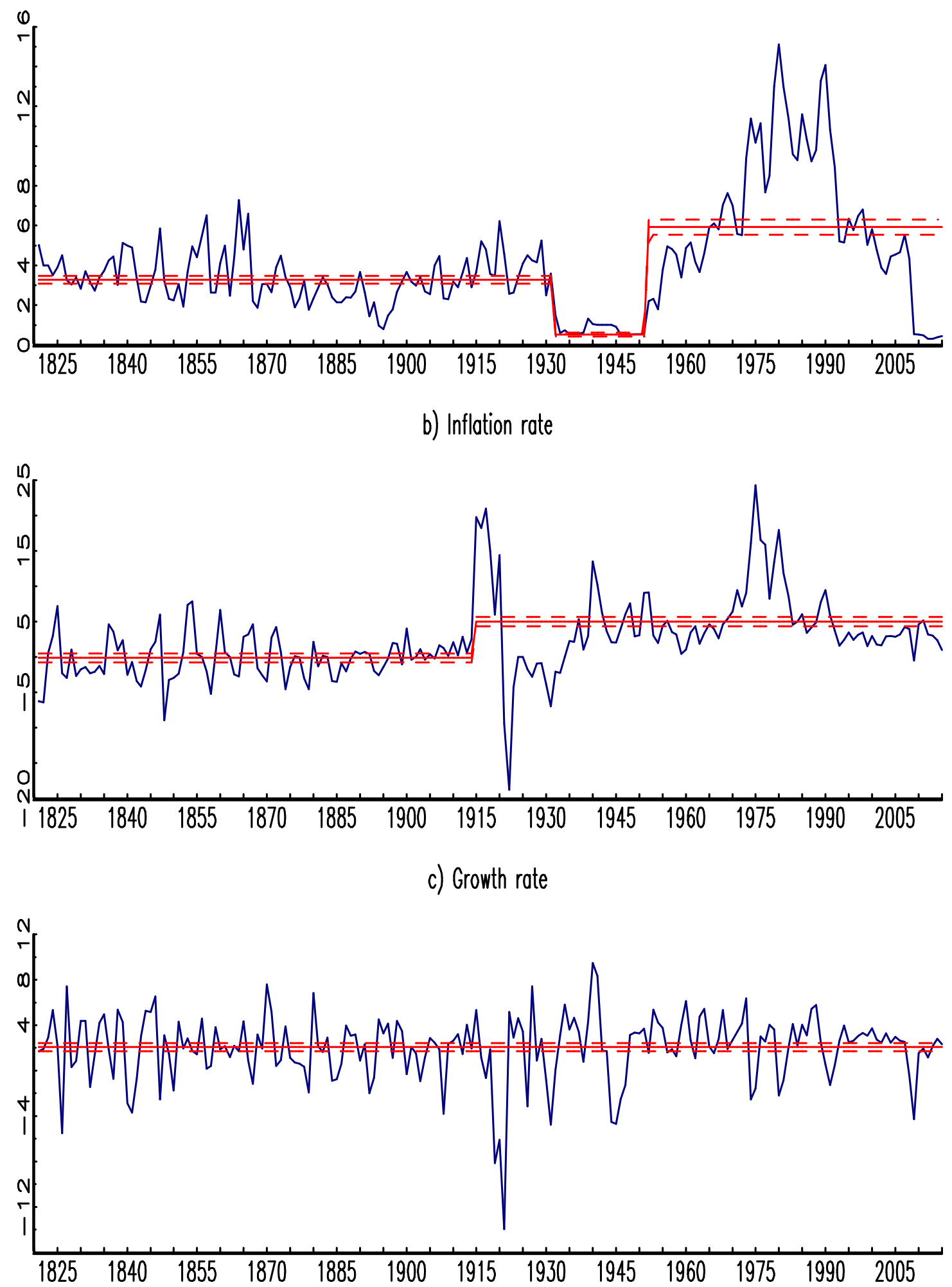

Figure 1: Notes: UK data 1820-2014. The graphs also indicate level shifts (in solid red) with $95 \%$ confidence intervals (in dashed red). 

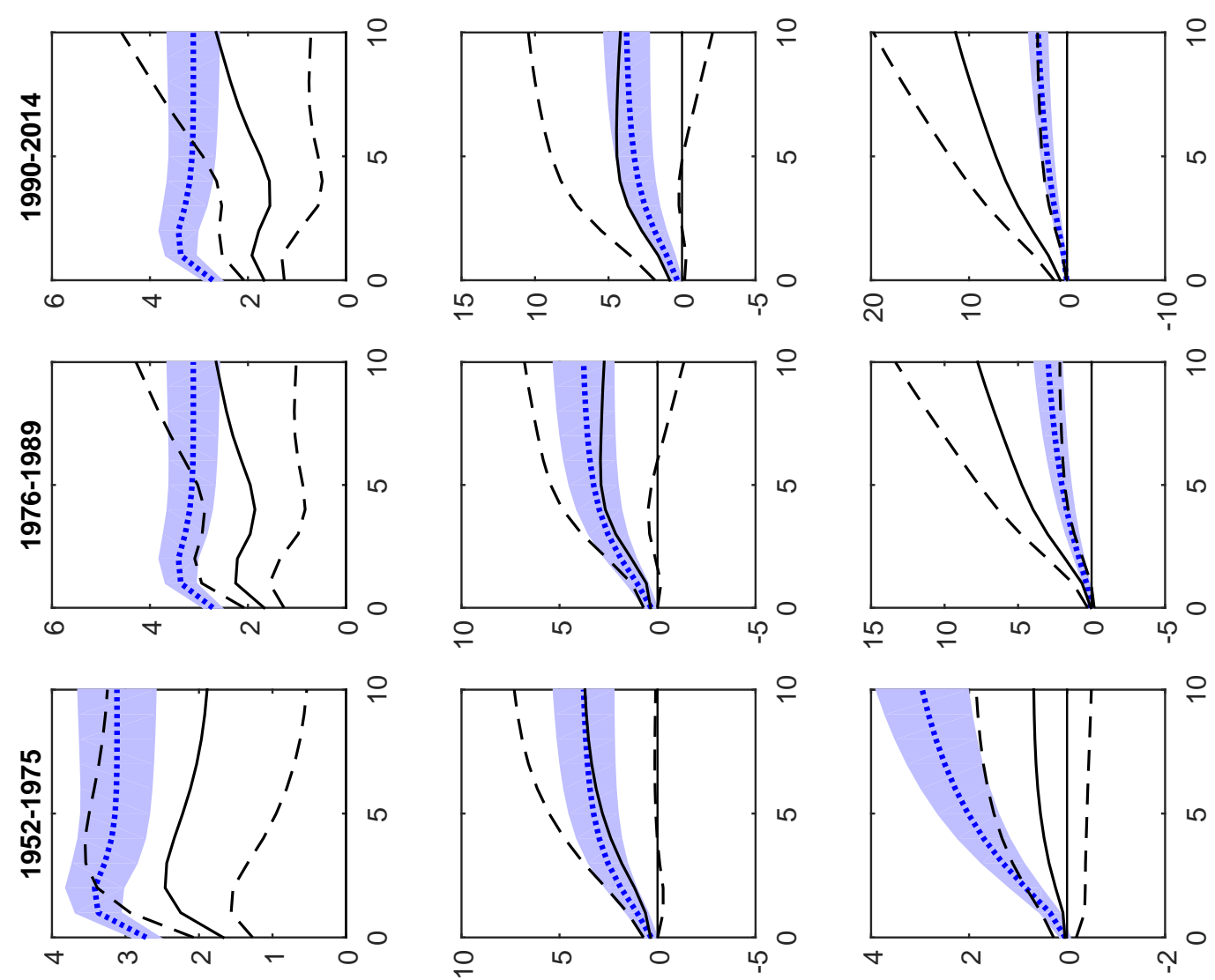

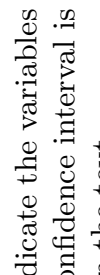

త్ష

总

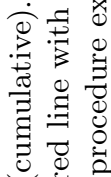

प्षै :
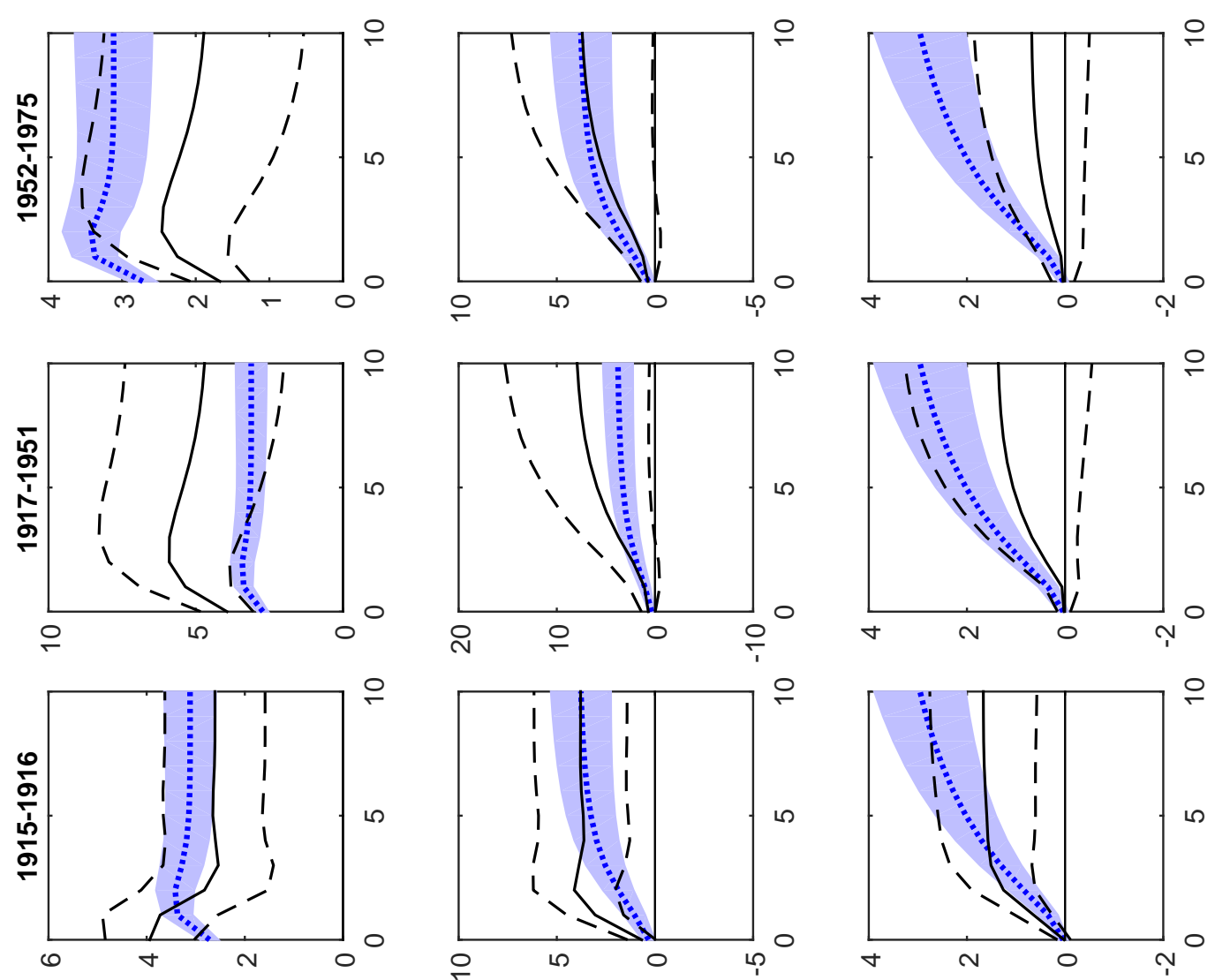

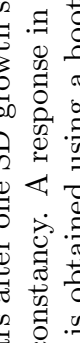

ซี

む

氙莡

कै

5 政

$\underset{0}{\mathbb{2}}$

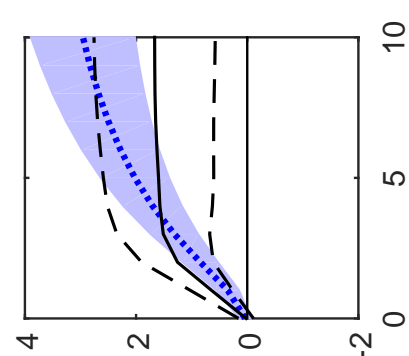

.

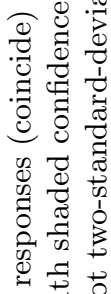
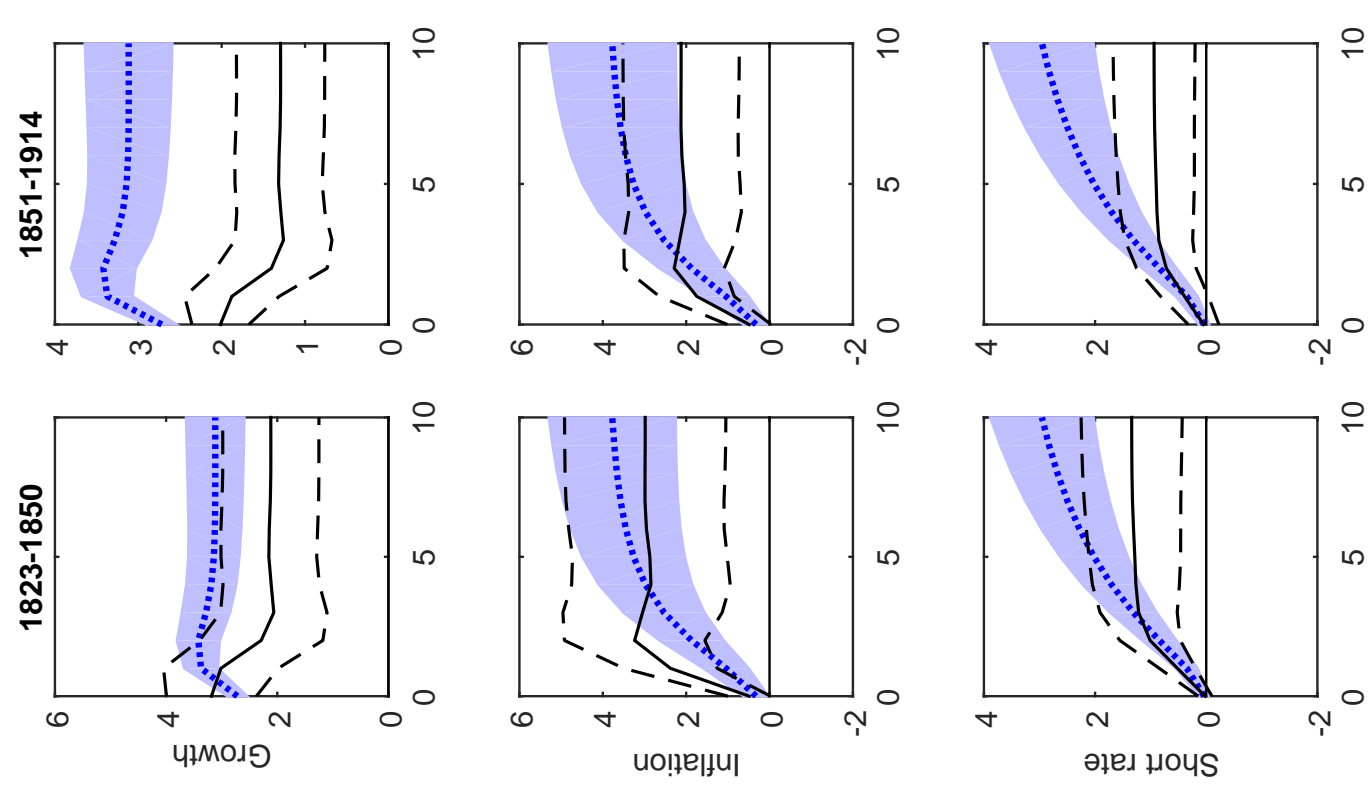

语

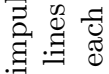

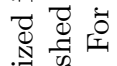

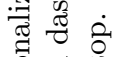

:

సٓ Ð

귱

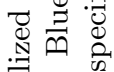

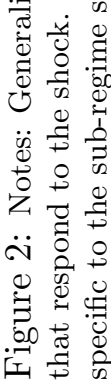



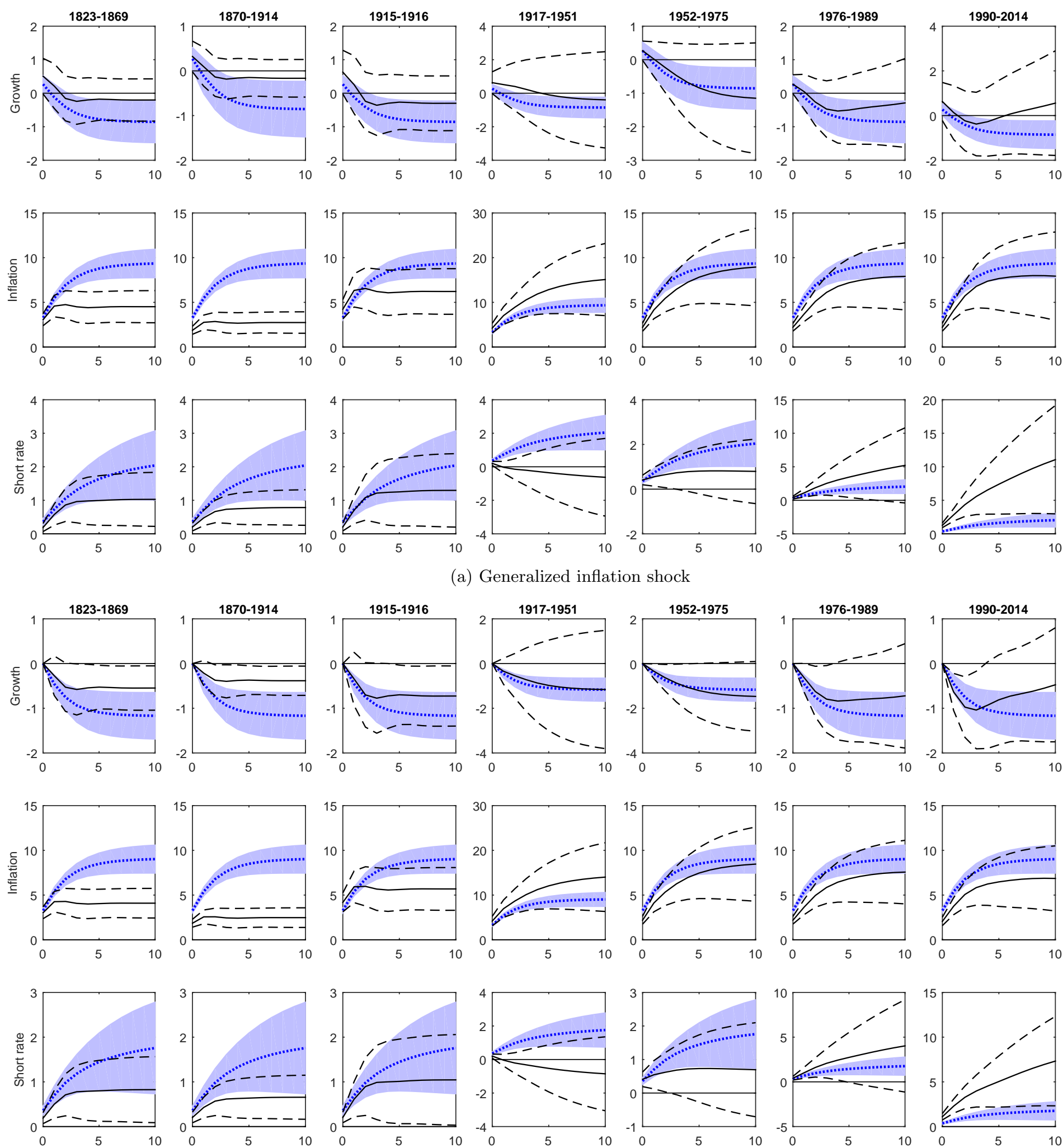

(b) Orthogonalized inflation shock

Figure 3: See Notes to Figure 2. Orthogonalized IRFs us an ordering of the variables as the growth rate first, then the inflation and finally the short rate. 

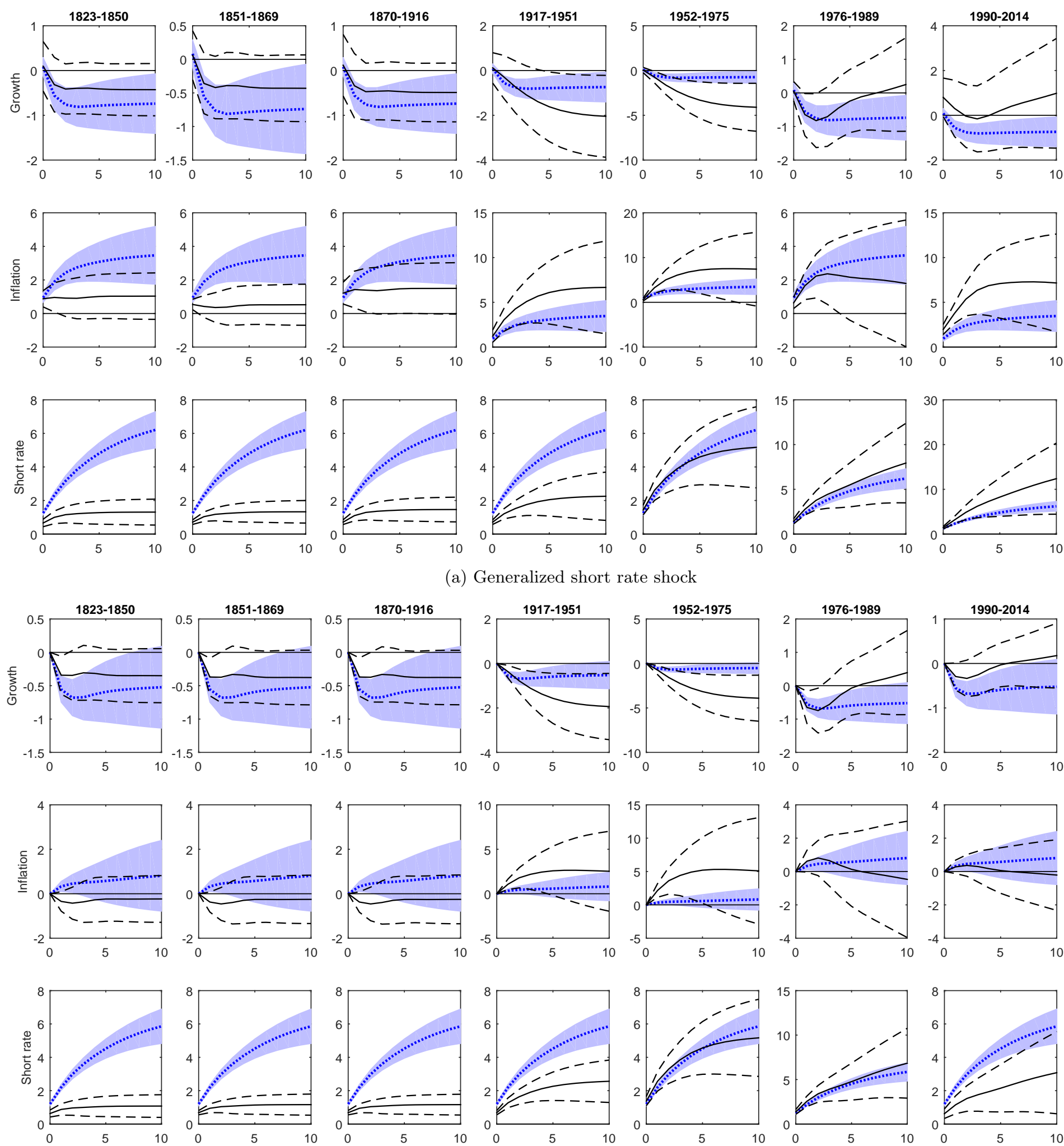

(b) Orthogonalized short rate shock

Figure 4: See Notes to Figures 2 and 3. 


\section{$7 \quad$ References}

Balke, N.S. \& K.M. Emery. 1994. The Federal funds rate as an indicator of monetary policy: Evidence from the 1980s, Federal Reserve Bank of Dallas Economic Review, First Quarter, 1-15.

Balke, N.S. 2000. Credit and economic activity: credit regimes and nonlinear propagation of shocks. Review of Economics and Statistics 82(2), 344-349.

Barro, R.J. 2013. Inflation and economic growth. Annals of Economics and Finance 14(1), 121-144.

Bataa, E., Osborn, D.R., Sensier, M. \& van Dijk, D. 2013. Structural breaks in the international dynamics of inflation. Review of Economics and Statistics 95 (2): 646-659.

2014. Identifying changes in mean, seasonality, persistence and volatility for G7 and Euro Area inflation. Oxford Bulletin of Economics and Statistics $76(3), 360-388$.

Bataa, E., Izzeldin, M. \& Osborn, D. 2016. Changes in the global oil market. Energy Economics 56, $161-176$.

Bataa, E., Osborn, D.R. \& Sensier, M. 2018. China's increasing global influence: Changes in international growth spillovers. Economic Modelling 74, 194-206.

Baumeister, C., Liu, P. \& Mumtaz, H. 2013. Changes in the effects of monetary policy on disaggregate price dynamics. Journal of Economic Dynamics and Control 37(3), 543-560.

. 2008a. Investigating inflation persistence across monetary regimes, Quarterly Journal of Economics 123, 1105-1160.

. 2008b. The 'Great Moderation' in the United Kingdom. Journal of Money, Credit and Banking 40 (1): 121-147.

Bernanke, B.S. \& A.S. Blinder. 1992. The Federal funds rate and the channels of monetary transmission. American Economic Review 82, 901-921.

Blanchard, O. \& Quah, D. 1989. The dynamic effects of aggregate demand and supply. American Economic Review 79, 655-673.

Boivin, J. \& Giannoni, M.P. 2006. Has monetary policy become more effective?. Review of Economics and Statistics 88(3), 445-462.

Cogley, T., Primiceri, G.E. \& Sargent, T.J. 2008. Inflation-gap persistence in the US. American Economic Journal: Macroeconomics 2(1). 43-69.

Cogley, T. \& Sargent, T.J. 2002. Evolving post world war II US inflation dynamics. In B. S. Bernanke \& K. Rogoff (Eds.), NBER macroeconomics annual 2001. Cambridge, US: MIT Press.

2005. Drifts and volatilities: monetary policies and outcomes in the post WWII US. Review of Economic Dynamics 8, 262-302.

Davidson R. \& J.G. MacKinnon. 1993. Estimation and Inference in Econometrics. Oxford University Press. New York.

Diebold, F.X. \& Yilmaz, K. 2009. Measuring financial asset return and volatility spillovers, with application to global equity markets. Economic Journal 119, 158-171.

2012. Better to give than to receive: predictive directional measurement of volatility spillovers (with discussion). International Journal of Forecasting 28, 57-66.

2014. On the network topology of variance decompositions: Measuring the connectedness of financial firms. Journal of Econometrics 182, 119-134

Evans, M., \& K. Lewis. 1995. Do expected shifts in inflation affect estimates of the long-run Fisher relation? Journal of Finance, 50 (March): 225-253.

Estrella, A. \& Hardouvelis, G.A. 1991. The term structure as a predictor of real economic activity. Journal of Finance 46(2), 555-576.

Fuhrer, J.C. \& Moore, G.R. 1995. Monetary policy, trade-offs and the correlation between nominal rates and real output. American Economic Review 85, 219-239.

Gambe, E.N. \& Joutz, F. 1993. The dynamic effects of aggregate demand and supply disturbances: Comment. American Economic Review 83, 1387-1393.

Ghosh, A. \& Phillips, S. 1998. Warning: inflation may be harmful to your growth. IMF Staff Papers $45,672-710$

Groen, J.J.J. \& Mumtaz, H. 2008. Investigating the structural stability of the Phillips curve relationship. Bank of England working paper: vol. 350.

Gylfason, T.\& Herbertsson, T.T. 2001. Does inflation matter for growth? Japan and the World Economy 13, 405-428.

Hanson, M.S. 2004. The "price puzzle" reconsidered. Journal of Monetary Economics 51(7),1385-1413.

Haug A.A. \& W.G. Dewald. 2011. Money, output, and inflation in the longer term: major industrial countries, 1880-2001. Economic Inquiry 50 (3), 773-787.

Irwin, D.A. 1988. Welfare effects of British free trade: debate and evidence from the 1840s. Journal of Political Economy 96, 1142-1164.

Khan, M.S. \& Senhadji, A.S. 2001. Threshold effects in the relationship between inflation and growth. IMF Staff Papers 48, 1-21.

Koop, G., Pesaran, M.H. \& Potter, S.M. 1996. Impulse response analysis in non-linear multivariate models. Journal of Econometrics 74, 119-147.

Lettau, M. \& van Nieuwerburgh, S. 2008. Reconciling the return predictability evidence. Review of Financial Studies 21(4), 1607-1652.

Lutkepohl, H. 1989. The stability assumption in tests of causality between money and income. In Econometrics of Structural Change; Kramer, W., Ed.; Springer-Verlag: New York, 75-86. 
Mishkin, F.S. 1992. Is the Fisher effect for real?: A reexamination of the relationship between inflation and interest rates. Journal of Monetary Economics 30 (2): 195-215.

Ng, S. \& Vogelsang, T.J. 2002. Analysis of vector autoregressions in the presence of shifts in mean. Econometric Reviews 21(3), 353-381.

Officer, L.H. 2015. What were the UK earnings and prices then? MeasuringWorth, http:www.measuringworth.com

Pesaran, M. H. \& Shin, Y. 1998. Generalized impulse response analysis in linear multivariate models. Economics Letters 58, 17-29.

Rapach, D.E. 2003. International evidence on the long-run impact of inflation. Journal of Money, Credit, and Banking. 35 (1): 23-48.

Sarel, M. 1996. Nonlinear effects of inflation on growth. IMF Staff Papers 43, 199-215.

Shiller, R.J. and P. Perron. 1985. Testing the random walk hypothesis: power versus frequency of observation. Economics Letters. 18. 381-86.

Sims, C.A. 1992. Interpreting the macroeconomic time series facts: The Effects of monetary policy. European Economic Review 36. 975-1000.

Sims, C. A. \& Zha, T. 2006. Were there regime switches in U.S. monetary policy? American Economic Review 96(1), 54-81.

Stock, J.H. and M.W. Watson. 1998. Median unbiased estimation of coefficient variance in a time varying parameter model. Journal of American Statistical Association 93, 349-358. 